\title{
Generation of developmentally competent oocytes and fertile mice from parthenogenetic embryonic stem cells
}

\author{
Chenglei Tian ${ }^{1,2}$, Linlin Liu ${ }^{1,2}$, Ming Zeng ${ }^{2}$, Xiaoyan Sheng ${ }^{1,2}$, Dai Heng ${ }^{1,2}$, Lingling Wang ${ }^{2}$, Xiaoying Ye ${ }^{1,2}$, \\ David L. Keefe ${ }^{3}$, Lin Liu ${ }^{1,2,4 \bowtie}$ \\ ${ }^{1}$ State Key Laboratory of Medicinal Chemical Biology, Nankai University, Tianjin 300071, China \\ 2 Department of Cell Biology and Genetics, College of Life Sciences, Nankai University, Tianjin 300071, China \\ 3 Department of Obstetrics and Gynecology, NYU Langone Health, 550 First Avenue, New York, NY 10012, USA \\ ${ }^{4}$ Institute of Translational Medicine, Tianjin Union Medical Center, Nankai University, Tianjin 300000, China \\ $\bowtie$ Correspondence: liulin@nankai.edu.cn (L. Liu) \\ Received May 22, 2021 Accepted June 20, 2021
}

\begin{abstract}
Parthenogenetic embryos, created by activation and diploidization of oocytes, arrest at mid-gestation for defective paternal imprints, which impair placental development. Also, viable offspring has not been obtained without genetic manipulation from parthenogenetic embryonic stem cells ( $p E S C s$ ) derived from parthenogenetic embryos, presumably attributable to their aberrant imprinting. We show that an unlimited number of oocytes can be derived from pESCs and produce healthy offspring. Moreover, normal expression of imprinted genes is found in the germ cells and the mice. pESCs exhibited imprinting consistent with exclusively maternal lineage, and higher X-chromosome activation compared to female ESCs derived from the same mouse genetic background. pESCs differentiated into primordial germ cell-like cells (PGCLCs) and formed oocytes following in vivo transplantation into kidney capsule that produced fertile pups and reconstituted ovarian endocrine function. The transcriptome and methylation of imprinted and X-linked genes in PESC-PGCLCs closely resembled those of in vivo produced PGCs, consistent with efficient reprogramming of methylation and genomic imprinting. These results demonstrate that amplification of germ cells through parthenogenesis faithfully
\end{abstract}

Chenglei Tian, Linlin Liu, and Ming Zeng: Equal contributions.

Supplementary Information The online version contains supplementary material available at https://doi.org/10.1007/s13238-02100865-4. maintains maternal imprinting, offering a promising route for deriving functional oocytes and having potential in rebuilding ovarian endocrine function.

KEYWORDS parthenogenetic embryonic stem cells, primordial germ cell-like cells, imprinting, meiosis, oocytes

\section{INTRODUCTION}

In most mammalian species, follicular reserve is determined at birth, and progressively declines with age. Both age and gonadotoxic chemo- or radio-therapies accelerate oocyte and follicular attrition and promote premature ovarian aging and infertility (Nagaoka et al. 2012; Grive and Freiman 2015; Zhang and Liu 2015). Augmenting the supply of oocytes could preserve the endocrine functions. Encouragingly, oocytes can be generated from embryonic stem cells (ESCs) derived from fertilized embryos or induced pluripotent stem cells (iPSCs) from somatic cells (Hayashi et al. 2012; Hikabe et al. 2016).

Parthenogenetic embryos, formed from activation and diploidization of oocytes, do not contain a paternal genome, such that parthenotes arrest at mid-gestation from defects in genomic imprinting and placental malfunction (Barton et al. 1984; Surani et al. 1984; Barlow and Bartolomei 2014). Despite their developmental incompetence, parthenogenetic embryonic stem cells ( $p E S C s$ ) can be generated from parthenogenetic embryos, and therefore allay ethical concerns associated with destruction of viable embryos (Sousa and Wilmut 2007). pESCs are produced from oocytes by chemical activation e.g., with strontium $\left(\mathrm{Sr}^{2+}\right)$ (Swann and 
Ozil 1994; Moses and Kline 1995; Liu et al. 2002; Chen et al. 2009), and undergo dramatic epigenetic reprogramming and global demethylation ( $\mathrm{Li}$ et al. 2009). The pESCs are minimally immunogenic to those who donate the founding oocytes (Kim et al. 2007; Didie et al. 2013; Espejel et al. 2014). Moreover, pESCs develop significantly fewer de novo coding mutations than do nuclear transfer ESCs and iPSCs (Johannesson et al. 2014). The utility of iPSCs is especially constrained by accumulation of somatic mutations and variability of differentiation (Blasco et al. 2011; Gore et al. 2011; Gao et al. 2015; Tapia and Scholer 2016; Kilpinen et al. 2017; Yoshihara et al. 2017; D'Antonio et al. 2018). Additionally, given that telomere reserve is critical for genomic stability and formation of germline (Bonis et al. 2014), telomeres of pESCs are comparable to those of ESCs (Yin et al. 2014). However, it remains unclear whether functional oocytes can be generated from pESCs and whether the aberrant imprinting of parthenogenetic embryos can be reprogrammed during formation of $\mathrm{pESCs}$ and differentiation into PGCLCs and oocytes.

\section{RESULTS}

Parthenogenetic ESCs (pESCs) acquire germline competence and maintain maternally expressed genes

We generated parthenogenetic ESCs (pESCs) from $\beta$-ActinGFP parthenogenetic embryos, and female (XX) ESCs from the same genetic background, to serve as controls (Fig. 1A). After seven days in culture, the outgrowths from parthenogenetic blastocysts exhibited morphology and size comparable to those of blastocysts developed from fertilized embryos, and expressed Actin-GFP (Fig. S1A). Morphology and expression of the pluripotent marker genes, Oct4 and Nanog in pESCs resembled those of ESCs (Fig. 1B and 1C). Both pESCs and ESCs generated chimeras with germline competence, as determined by the 4-8-cell embryo injection assay (Fig. 1D-F). Various pESC lines obtained from MII oocytes demonstrated germline competence (Fig. 1G). pESC lines generated from different mouse strains exhibited variability in the efficiency of cell line derivation from blastocysts, from $22 \%$ to $57 \%$. The efficiency of germline transmission ranged from $33 \%$ to $60 \%$ (Fig. 1G). Of five female ESC lines derived from 19 blastocysts, two displayed germline competence (Fig. 1G). At passage 10, over $65 \%$ of chromosome spreads from pESCs displayed the normal complement of 40 chromosomes (Fig. S1B), similar to ESCs. These results demonstrate that pESCs derived from parthenogenetically activated oocytes exhibit pluripotency and developmental potential comparable to female ESCs.

To characterize the molecular basis underlying their pluripotency, we employed RNA-seq analysis to compare the transcriptional profiles of pESCs to female ESCs. Genome-wide gene expression profile was strikingly similar $\left(R^{2}=\right.$ 0.98), but not identical between pESCs and ESCs (Fig. 2A). Like ESCs, pESCs expressed key pluripotency genes, including Oct4, Sox2, and Nanog, at high levels. Expression levels of naive marker genes also were similar between pESCs and ESCs (Fig. 2B and 2C). Expression levels of maternal genes, such as H19, Slc22a18, Grb10, Igf2r and Rhox5, in pESCs exceeded those of ESCs (Fig. 2D and 2E). Expression levels of paternal genes including lgf2, Snrpn, Mest, Impact, and Sgce were lower in pESCs than in ESCs (Fig. 2D and 2E), consistent with the maternal origin of pESCs. Comparison by GO analysis of upregulated genes between pESCs and ESCs showed enrichment for meiotic cell cycle and germ cell development in pESCs (Figs. S1C and S1D). X-linked genes were expressed at similar levels in pESCs and ESCs (Fig. 2F), but more upregulated than downregulated genes were found in X-chromosomes from pESCs (Fig. 2G). Upregulated genes from pESCs were enriched for those involved in germ cell development and meiosis (e.g., XIr, XIr3a, XIr3b, XIr3c, XIr4a, XIr4b, XIr4c, XIr5c, 1700013H16Rik etc.) (Fig. 2H). These results imply that both ESCs and pESCs have two active $X$ chromosomes, but comparatively more $\mathrm{X}$-linked genes are upregulated indicative of higher $X$ chromosome activation in pESCs than in ESCs. $X$ chromosome re-activation represents important molecular criteria for naïve pluripotency of female ESCs (Huang et al. 2014; Pasque et al. 2014; Theunissen et al. 2016). Also, germ cells derived by differentiation of embryoid bodies (EBs) from pESCs exhibit higher expression of germ cell genes than those of ESCs (Liu et al. 2011).

\section{Comparison of pESC-derived PGCLCs with embryonic PGCs at global transcriptional levels}

To test the hypothesis that pESCs could provide a rich source of germ cell induction and functional oocytes, we induced PGCLCs from pESCs and compared them to PGCLCs from XX ESCs, following the protocol described previously for induction of PGCLCs from ESCs and iPSCs (Hayashi et al. 2012; Hayashi and Saitou 2013). PGCLCs derived from XX ESCs and pESCs also were compared to embryonic PGCs in vivo. pESCs and XX ESCs from the same inbred genetic background formed epiblast-like cells (EpiLCs) and PGCLCs (Fig. 3A) at similar efficiencies $(8.12 \% \pm 0.56 \%$ for pESC-PGCLCs and $6.50 \% \pm 1.24 \%$ for ESC-PGCLCs) by FACS (SSEA1 and CD61 double positive cells indicative of PGCLCs) (Hayashi et al. 2012; Hikabe et al. 2016) (Fig. 3B). Absence of the antibodies served as negative control. pESCs from hybrid genetic background exhibited higher efficiency in the induction of PGCLCs (9.58\% $\pm 0.54 \%$ in C57BL/6XC3HF1 pESCs and $10.53 \% \pm$ $0.47 \%$ in C57BL/6X129F1 pESCs), compared to those of inbred pESCs $(P<0.05)$ (Fig. 3B). To understand the underlying molecular changes in the PGCLCs derived from pESCs, we performed RNA-seq analysis of these cells and compared them to those of ESCs and ESC-PGCLCs. Broadly, transcriptome profile between pESC-PGCLCs and ESC-PGCLCs was similar, yet some differences were found 
A

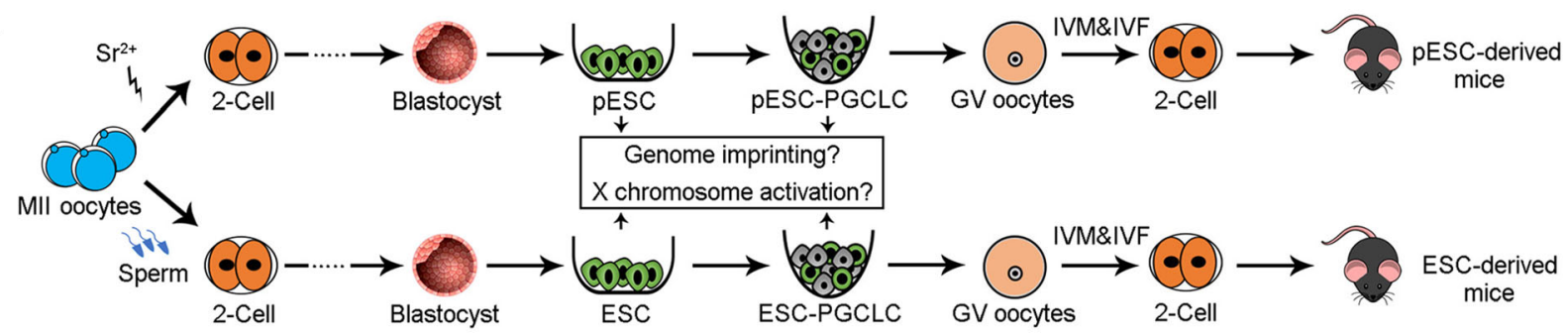

B

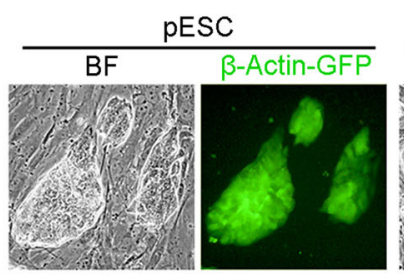

C

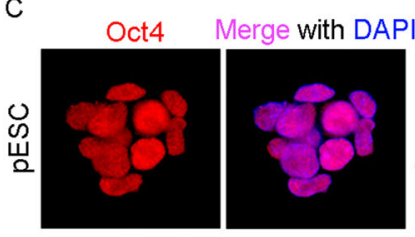

Oct4 Merge with DAPI

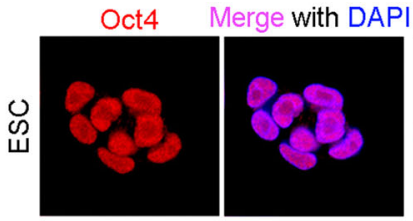

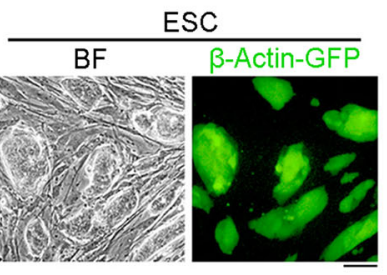

Nanog Merge with DAPI

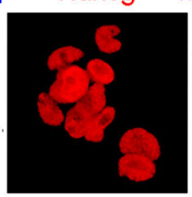

Nanog
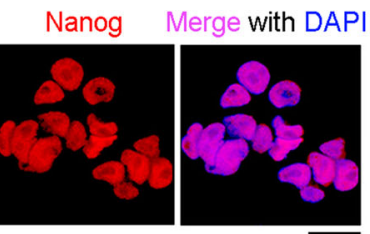

D
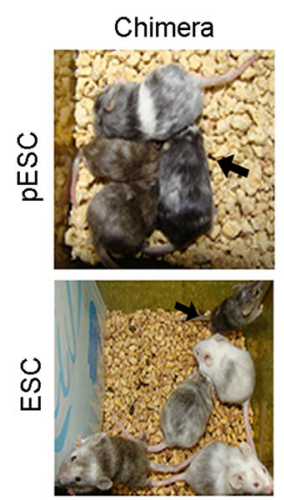

E



$F$

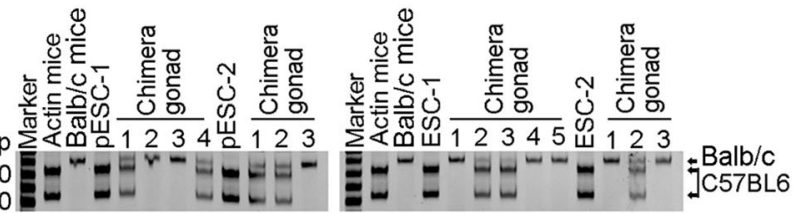

G

\begin{tabular}{|c|c|c|c|c|c|}
\hline Cell type & Strain & $\begin{array}{c}\text { MII } \\
\text { oocytes }\end{array}$ & $\begin{array}{l}\text { Blastocysts } \\
(\%)\end{array}$ & $\begin{array}{l}\text { Cell line } \\
(\%)\end{array}$ & $\begin{array}{c}\text { Cell line } \\
\text { with GT (\%) }\end{array}$ \\
\hline \multirow{5}{*}{$\mathrm{pESC}$} & $\begin{array}{l}\text { Actin-GFP } \\
\text { (C57BL/6) }\end{array}$ & 32 & $12(37.5)$ & $6(50.0)$ & 2/6 (33.3) \\
\hline & $\begin{array}{l}\text { Nanog-GFP } \\
\text { (C57BL/6X129F1) }\end{array}$ & 39 & $16(41.0)$ & $5(31.3)$ & $1 / 2(50.0)$ \\
\hline & $\begin{array}{l}\text { Oct4-GFP } \\
\text { (C57BL/6XCBAF1) }\end{array}$ & 16 & $9(56.3)$ & $4(44.4)$ & NA \\
\hline & C57BL/6XC3HF1 & 36 & $28(77.8)$ & $16(57.1)$ & $3 / 5(60.0)$ \\
\hline & C57BL/6X129F1 & 76 & 54 (71.1) & $12(22.2)$ & NA \\
\hline $\begin{array}{l}\text { Female } \\
\text { ESC }\end{array}$ & $\begin{array}{l}\text { Actin-GFP } \\
\text { (C57BL/6) }\end{array}$ & NA & 19 & $5(26.3)$ & $2 / 5(40.0)$ \\
\hline
\end{tabular}

Figure 1. Parthenogenetic ESCs (pESCs) acquire germline competence. (A) Schematic summary illustrating the strategy of augmenting oocytes by derivation of pESCs from parthenogenetically activated oocytes or ESCs from fertilized embryos that are directed to differentiate into germ cells and functional oocytes. IVM, in vitro maturation; IVF, in vitro fertilization. (B) Morphology and $\beta$ Actin-GFP expression of pESCs and ESCs. Scale bar $=100 \mu \mathrm{m}$. (C) Expression of pluripotency markers (Oct4 and Nanog) of pESCs and ESCs. Scale bar $=20 \mu \mathrm{m}$. (D and E) Chimera (D) and germline competency (E) of pESCs and ESCs by 4-8-cell embryo injection. Germline offspring was produced by mating of chimeras with albino ICR mice. Albino Balb/c mice served as embryo donors, and pseudo-pregnant albino Kunming mice as surrogate mother. (F) Genotyping analysis of gonad in pESC (left) and ESC (right) derived chimeras generated from pESCs or ESCs by microsatellite primers D12Mit136. (G) Summary of derivation of pESCs and female ESCs from various mouse strains. Actin-GFP and Oct4-GFP pESCs were from in vivo (IVO) MII oocytes; Nanog-GFP pESCs from in vitro maturation (IVM) MII oocytes; C57BL/6XC3HF1 and C57BL/6X129F1 pESCs from IVO and IVM oocytes. NA, not available; GT, germline transmission competence; the efficiency (\%) of GT cell lines is shown as the number of cell lines with germline transmission competence/number of cell lines tested. 
A

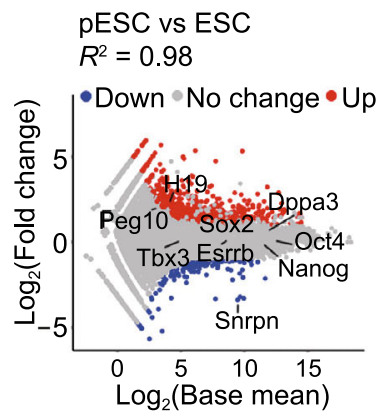

pESC vs ESC

E

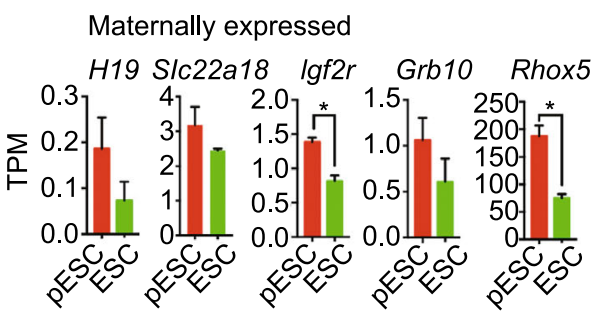

Paternally expressed

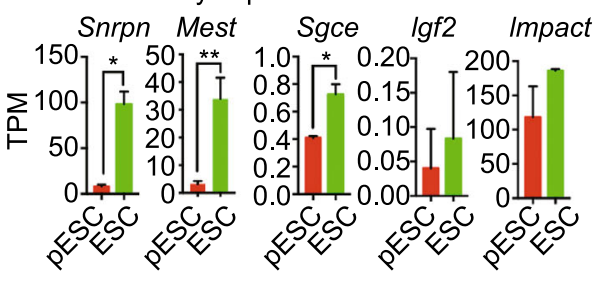

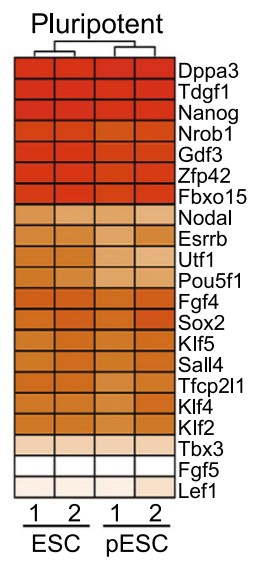

C

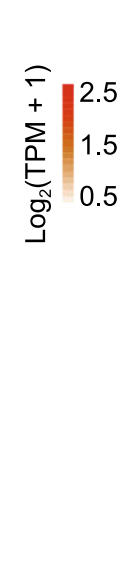

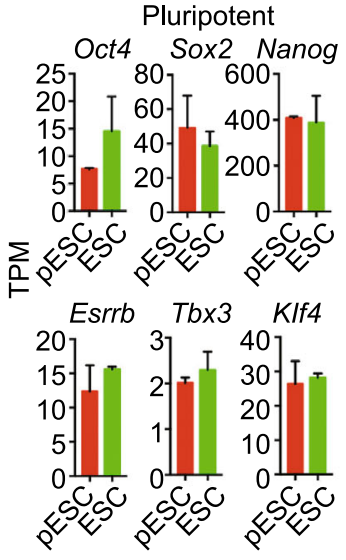

D Maternally expressed

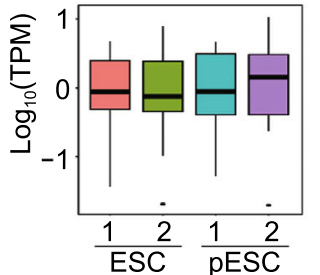

Paternally expressed



F

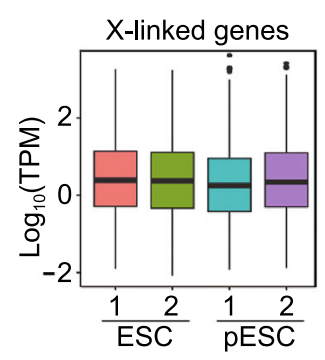

G

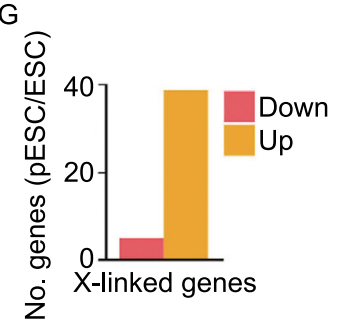

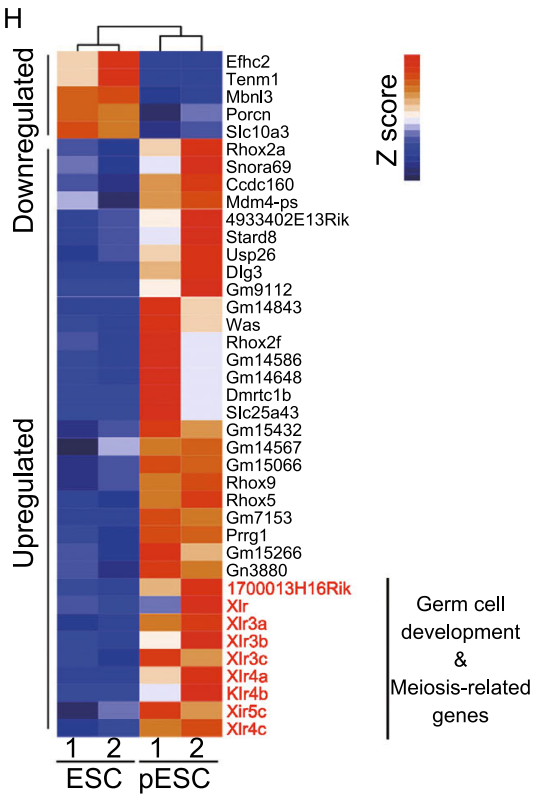

Figure 2. Parthenogenetic ESCs (pESCs) maintain expression of maternal genes. (A) Scatter-plots showing the differential gene expression profile between pESCs and ESCs. Two-fold changes $(P<0.05)$ are set as threshold. (B) Heatmap displaying similar expression profile of pluripotency genes between pESCs and ESCs. (C) Comparison of expression of representative pluripotency genes in pESCs and ESCs by RNA-seq. Data shown as mean \pm SEM. (D) Box plot showing higher levels of maternally expressed genes but lower levels of paternally expressed genes in pESCs than in ESCs. (E) Expression of representative maternally and paternally expressed genes in pESCs and ESCs by RNA-seq. Data shown as mean \pm SEM. (F) Box plot displaying expression profile of all X-linked genes in pESCs compared with that of ESCs. (G) More upregulated than downregulated X-linked genes in pESCs compared with ESCs. The threshold of differentially expressed genes (DEGs) is $\geq 2$-fold $(P<0.05)$. (H) Typical upregulated and downregulated X-linked genes of pESCs compared with ESCs $(\geq 2$ fold change, $P<0.05)$. Genes in red, germ cell development or meiosis. All RNA-seq analysis represents two biological replicates.

(Fig. S2A and S2B). pESCs/ESCs and their respective PGCLCs were readily distinguishable at genome-wide level (Fig. S2B-D), consistent with previous findings (Zhou et al. 2016). Compared with those of pESCs or ESCs by KEGG analysis, most upregulated genes in pESC-PGCLCs and ESC-PGCLCs were enriched in signaling pathways regulating pluripotent stem cells (PSC), TGF- $\beta$ and Wnt (Fig. S2D and S2E) (Ohinata et al. 2009; Zhou et al. 2016). By GO analysis, the processes of reproductive system development and meiotic cell cycle were activated in both pESC- and ESC-PGCLCs (Fig. S2D and S2F). Global gene expression was comparable among pESC-PGCLCs, ESC-PGCLCs, and E12.5 PGCs. The correlation coefficient $\left(R^{2}\right)$ between pESC-PGCLCs and ESC-PGCLCs was 0.70 (Fig. S2G). 

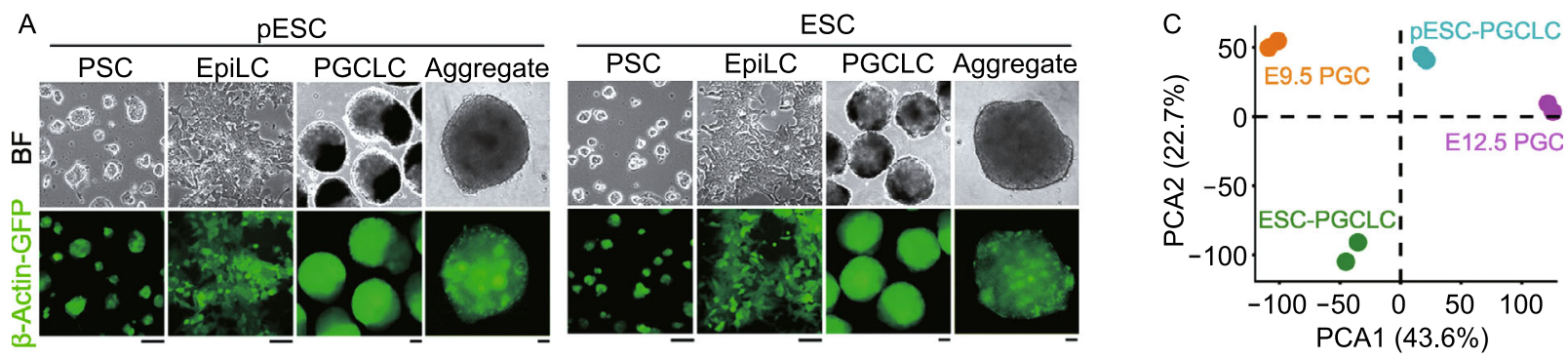

B
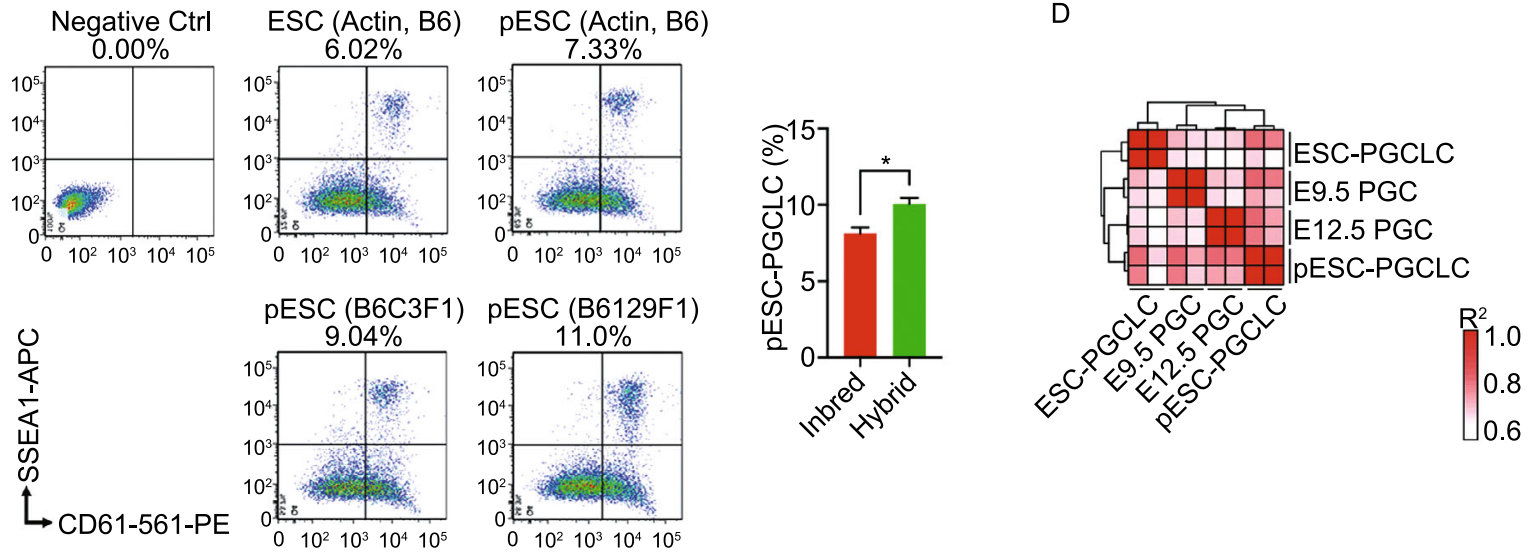

E Early PGC marker genes



F

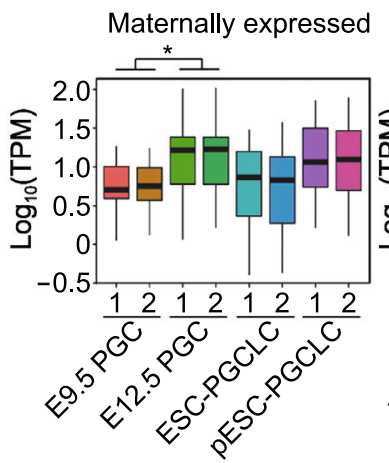

Paternally expressed

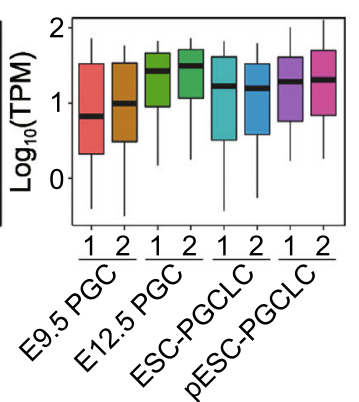

G

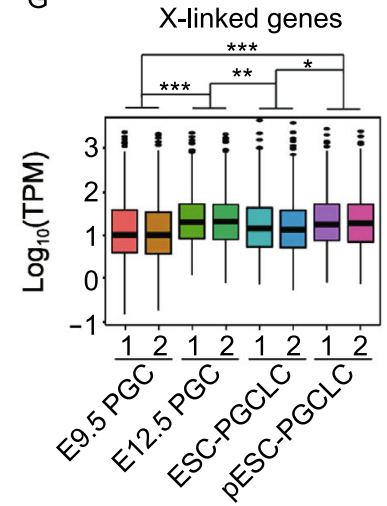

Figure 3. Comparison of pESC-PGCLCs and PGCs in vivo at global transcription levels and in imprinting. (A) Epiblast-like cells (EpiLCs) and PGCLCs induced from pESCs or ESCs bearing Actin-GFP, and aggregates of PGCLCs with E12.5 gonad somatic cells sorted from albino ICR mice for one day. Scale bar $=50 \mu \mathrm{m}$. (B) Representative PGCLCs induction (left) from pESCs or ESCs from Actin-GFP C57BL/6 mice, or pESCs from hybrid mice (C57BL/6XC3HF1 or C57BL/6X129F1) by FACS, and statistics (right) of PGCLCs induction efficiency from inbred (Actin, B6) and hybrid pESCs. Three replicates for inbred ESCs and pESCs and two replicates for hybrid pESCs. SSEA1 and CD61 double-positive cells represent PGCLCs. Absence of the antibody served as negative control. (C) PCA analysis by RNA-seq of E9.5 PGCs, E12.5 PGCs and pESC- or ESC-PGCLCs. (D) Pearson's correlation coefficient $\left(R^{2}\right)$ graph of E9.5 PGCs, E12.5 PGCs, pESC-PGCLCs and ESC-PGCLCs. The value of 1.0 represents perfect positive correlation and 0 represents no correlation between the two samples. (E) Heatmap showing the expression profile of early PGC marker genes in E9.5 PGCs, E12.5 PGCs, ESC-PGCLCs and pESC-PGCLCs. Gene expression level is shown as $\log _{10}(T P M+1)$. (F) Box plot displaying expression profile of maternal and paternal genes in E9.5 PGCs, E12.5 PGCs, and pESC- or ESC-PGCLCs. (G) Box plot displaying expression profile of $X$ chromosome-linked genes in E9.5 PGCs, E12.5 PGCs, and pESC- or ESC-PGCLCs. Data shown as Mean \pm SEM. ${ }^{\star} P<0.05,{ }^{\star \star} P<0.01,{ }^{\star \star \star} P<0.001$. All RNA-seq analysis represents two biological replicates.

We further compared the transcriptome of pESC- or ESCPGCLCs to that of E9.5 and E12.5 PGCs in vivo by PCA and clustering analysis. The global transcriptional profile of each sample can be clearly defined and separated (Fig. 3C and 


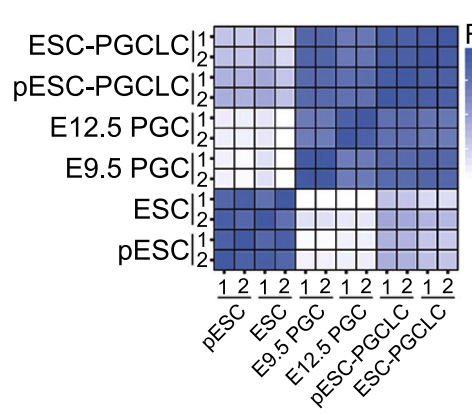

D

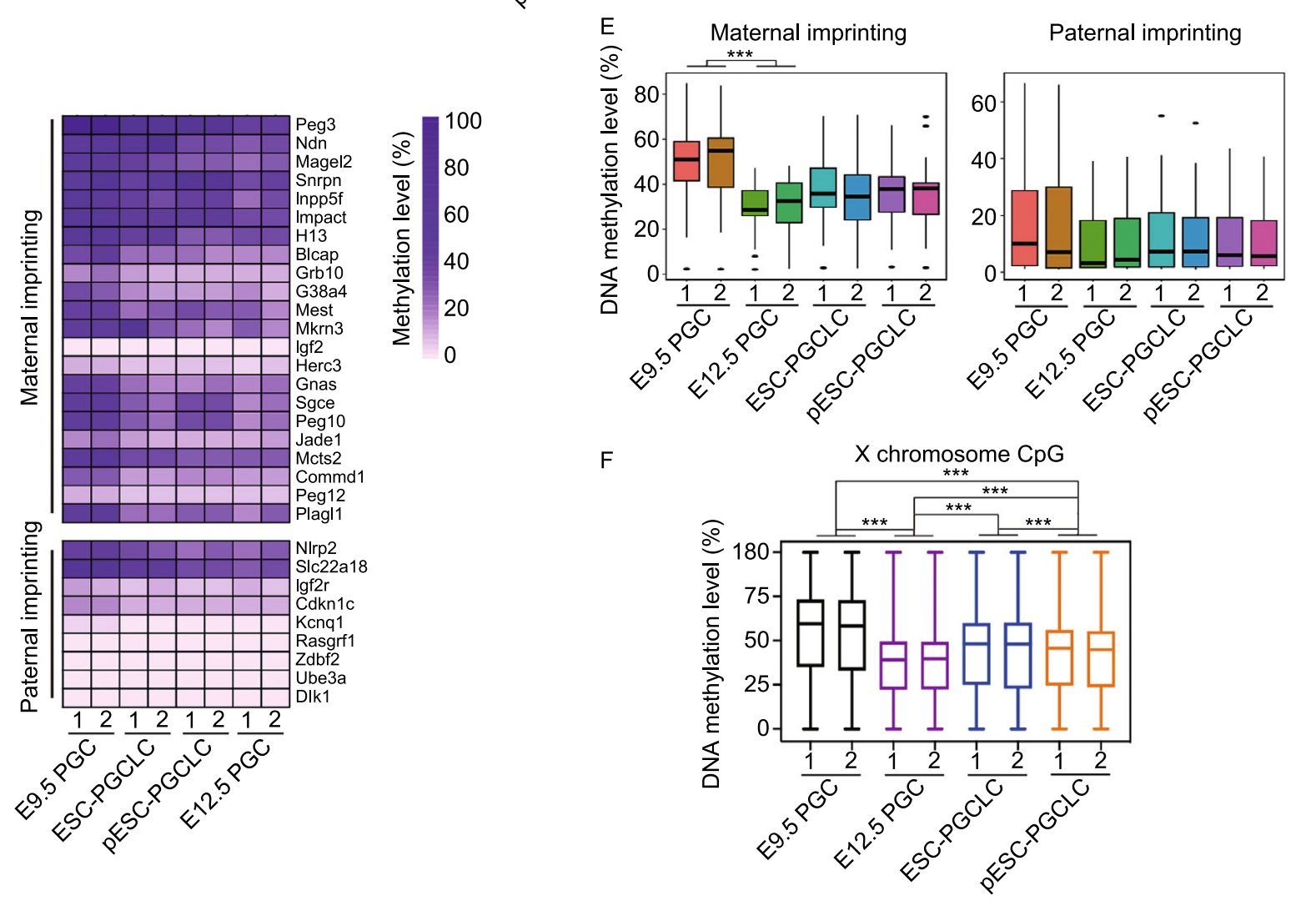

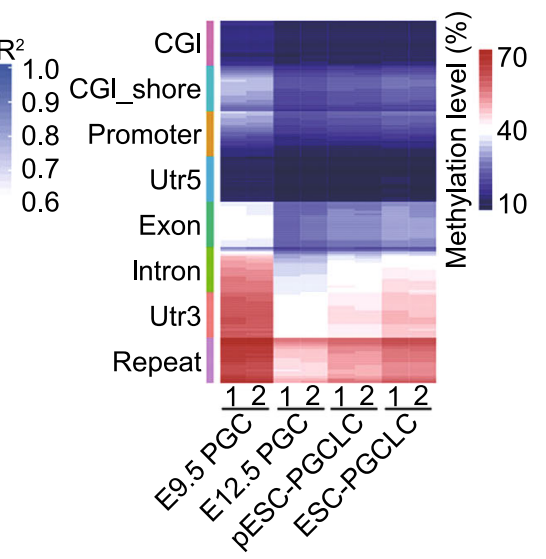

C

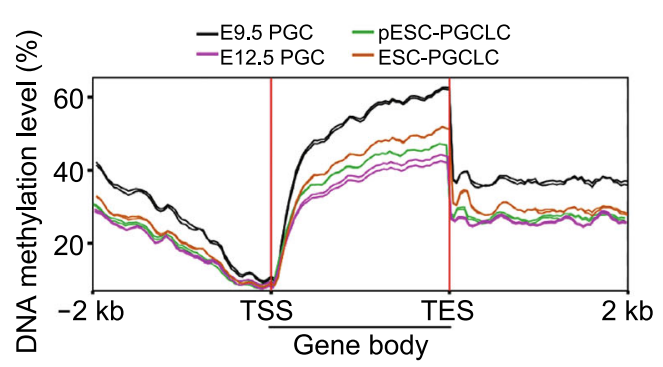

Figure 4. Comparison of pESC-PGCLCs and PGCs at DNA methylation levels. (A) Correlation factors of genome-wide DNA methylation levels in E9.5 PGCs, E12.5 PGCs, ESC-PGCLCs and pESC-PGCLCs as well as ESCs and pESCs. (B) Heatmap showing genome-wide DNA methylation levels at different gene regions of E9.5 PGCs, E12.5 PGCs, ESC-PGCLCs and pESCPGCLCs. (C) Genome-wide DNA methylation level in gene body regions including up- and down-stream 2 kb of gene body. (D) Methylation level of maternal and paternal imprinting genes in pESC-PGCLCs, ESC-PGCLCs, E9.5 PGCs and E12.5 PGCs. Methylation counts are provided in Table S1. (E) Box plot showing DNA methylation levels of maternal and paternal imprinting in pESC-PGCLCs, ESC-PGCLCs, E9.5 PGCs and E12.5 PGCs. (F) Box plot showing global DNA methylation levels of $X$ chromosomes in pESC-PGCLCs, ESC-PGCLCs, E9.5 PGCs and E12.5 PGCs. Data shown as mean \pm SEM. ${ }^{*} P<0.05,{ }^{* *} P<0.01 ;{ }^{* *} P<0.001$. RRBS analysis represents two biological replicates. 
3D). Based on the current induction methods, PGCLCs generated from ESCs or iPSCs resemble PGCs in their increased expression of early germ cell marker genes (Hayashi et al. 2012; Ohta et al. 2017; Hackett et al. 2018). Notably, the early PGC marker gene expression pattern, based on the published gene list (Miyauchi et al. 2017), was similar among pESC-PGCLCs, ESC-PGCLCs, and E9.5 and E12.5 PGCs (Fig. 3E).

\section{DNA methylation in pESCs and ESCs as well as in PGCLCs derived from pESCs or ESCs and PGCs in vivo}

An important aspect of germ cell development is erasure of genomic imprints in PGCs. Erasure of imprints begins in migrating PGCs and is essential for forming functional germ cells (Seisenberger et al. 2012; Kagiwada et al. 2013; Miyoshi et al. 2016). Differences in DNA methylation between maternal and paternal alleles of imprinted genes are laid down in a sex specific manner in male and female gametes (Davis et al. 2000; Lucifero et al. 2002). For instance, PGCs undergo demethylation in $\operatorname{lgf} 2 r$ and $\mathrm{H} 19$ genes (Geijsen et al. 2004). We analyzed expression profiles of imprinted genes in pESC- and ESC-PGCLCs and compared them to E9.5 and E12.5 PGCs. Overall expression levels of maternal and paternal genes did not differ significantly between pESC-PGCLCs and ESC-PGCLCs (Fig. 3F). These results demonstrate that imprinted genes are increasingly expressed during differentiation of PSCs into PGCLCs, corroborating significant demethylation during PGC development, as reported previously (Miyoshi et al. 2016; Meyenn et al. 2016).

$X$ chromosomes gradually reactivate in PGCs from E9.5 to E12.5 (S. M. Chuva de Sousa Lopes et al. 2008; Seisenberger et al. 2012). In line with this, expression levels of X-linked genes in E9.5 PGCs appeared to be lower than those of E12.5 PGCs as well as of pESC-PGCLCs or ESCPGCLCs (Fig. 3G). These data indicate that PGCLCs differentiated from pESCs or ESCs exhibit similar high rates of X-chromosome activation, resembling E12.5 PGCs.

Also, we compared DNA methylation profile of pESCs and ESCs by reduced representation bisulfite sequencing (RRBS). Genome-wide DNA methylation profile revealed very similar DNA methylation landscapes between pESCs and ESCs (Fig. S3A and S3B). Furthermore, we explored the DNA methylation profiles of $X$ chromosomes and imprinted genes. The overall DNA methylation levels on $X$ chromosomes in pESCs resembled that of XX ESCs (Fig. S3C). Parental imprinting is a heritable epigenetic mechanism resulting in parent-specific monoallelic expression of a subset of genes. DNA methylation levels of maternally expressed (paternally imprinted) genes did not differ between pESCs and ESCs, but DNA methylation levels of paternally expressed (maternally imprinted) genes (e.g., Snrpn, Impact, Mest, and Sgce) were higher in pESCs than in ESCs (Fig. S3D and S3E). Higher methylation of some maternally imprinted genes in pESCs mirrors their decreased expression levels (Figs. 2E and S3E).

After we established the similarly high quality of those pES cell lines and were confident about their germline capacity by chimera production assay, we focused on directed differentiation in vitro of PGCLCs from pESCs or ESCs, and compared the methylome of PGCLCs from pESCs or ESCs with that of in vivo E9.5 or E12.5 PGCs. ESC-PGCLCs, pESC-PGCLCs, E9.5 PGCs and E12.5 PGCs in vivo exhibited strikingly similar global methylation patterns $\left(R^{2}>0.90\right)$ (Fig. 4A). Global methylation levels of naive ESCs/pESCs generally were similar to those of PGCs in vivo (Fig. S4A and S4B), like previous reports, although EpiLCs displayed notably higher methylation levels (Meyenn et al. 2016; Shirane et al. 2016). We did not measure the methylation levels of EpiLCs during PGCLC induction. The methylation levels in different regions of the genome, including $\mathrm{GCl}$, promoter, Utr5, Exon, etc., were lower in E12.5 PGCs, pESC-PGCLCs and ESC-PGCLCs than in E9.5 PGCs (Figs. 4B, S4A and S4B). Also, global methylation levels of gene body regions $( \pm 2 \mathrm{~kb}$, including TSS and TES) were lower in E12.5 PGCs, pESC-PGCLCs and ESCPGCLCs than in E9.5 PGCs (Fig. 4C). These data demonstrate that despite heterogeneity of cell lines, PGCLCs induced from PSCs generally mimic PGCs in vivo (Hajkova et al. 2002; Seisenberger et al. 2012), also consistent with previous findings of methylome dynamics of PGCLC induction from PSCs (Meyenn et al. 2016; Shirane et al. 2016).

Methylation also regulates expression of imprinted genes in germ cells (Reik et al. 2001). The transcriptional profile of PGCs is tightly controlled, despite global hypomethylation, and sequences that carry long-term epigenetic memory (imprints, $\mathrm{CpG}$ islands on the $\mathrm{X}$ chromosome, and germlinespecific genes) become demethylated in late PGCs (Seisenberger et al. 2012; SanMiguel and Bartolomei 2018). DNA methylation levels of most imprinted genes in E9.5 PGCs exceeded those of E12.5 PGCs as well as of pESCand ESC-PGCLCs (Fig. 4D and 4E; Table S1), implying that loss of imprinting takes place during PGC development (Meyenn et al. 2016). DNA methylation levels of maternally and paternally imprinted genes in pESC-PGCLCs broadly were similar to those of ESC-PGCLCs and also PGCs in vivo (Fig. 4D and 4E; Table S1). Moreover, overall DNA methylation levels on $X$ chromosomes in E12.5 PGCs were lower than those of E9.5 PGCs (Fig. 4F). Indeed, the majority of PGCs entering the genital ridge at E10.5-13.5 days reactivate their $X$ chromosomes (Tam et al. 1994). The overall methylation levels of $X$ chromosomes in pESC-PGCLCs turned to be more similar to those of ESC-PGCLCs and E12.5 PGCs than of E9.5 PGCs (Fig. 4F). These results suggest that the genome of pESC-PGCLCs is relatively hypomethylated, with two active $\mathrm{X}$ chromosomes. 

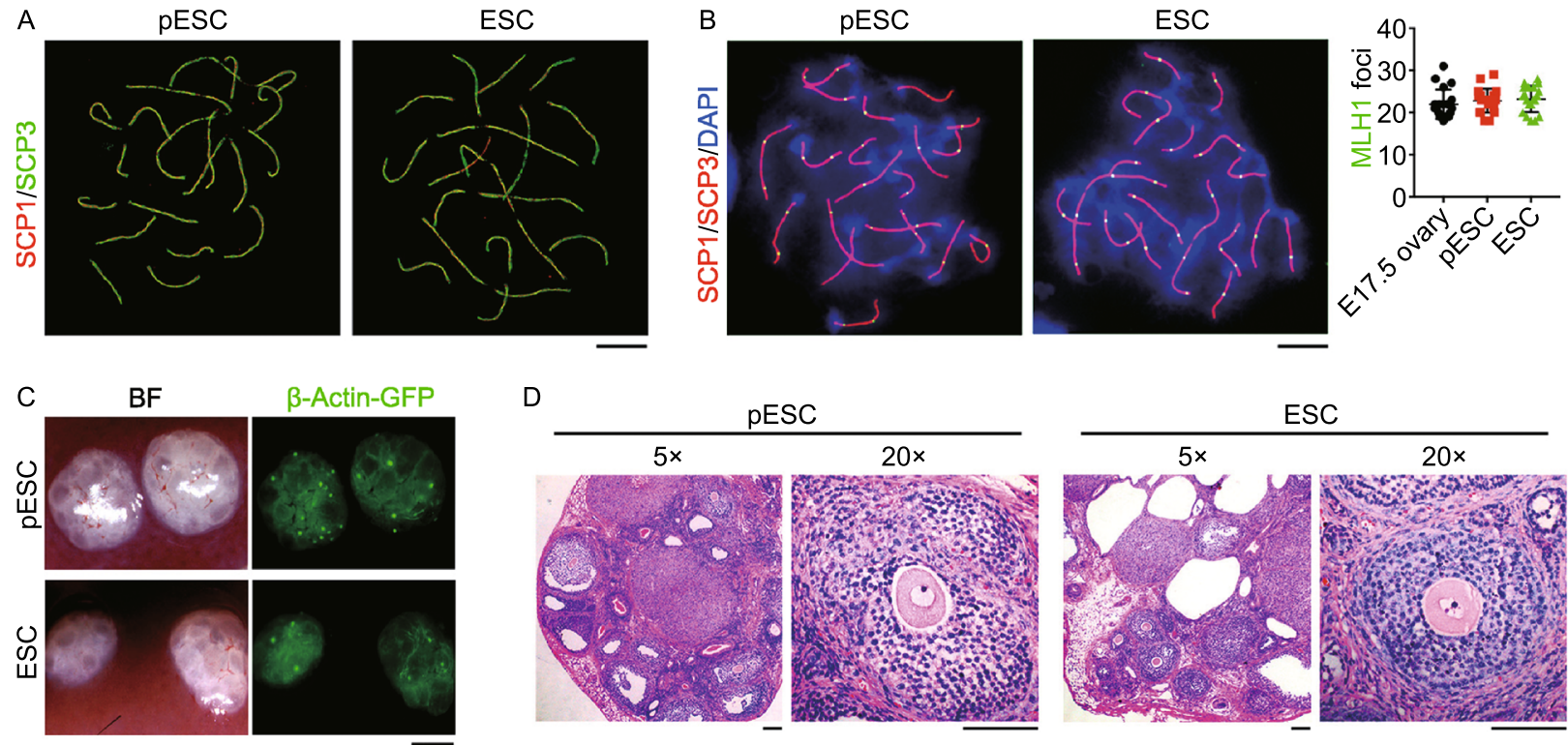

B-Actin-GFP

D

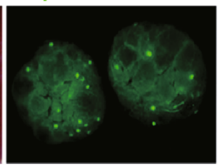

E

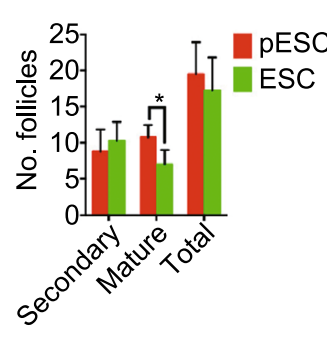
pESC

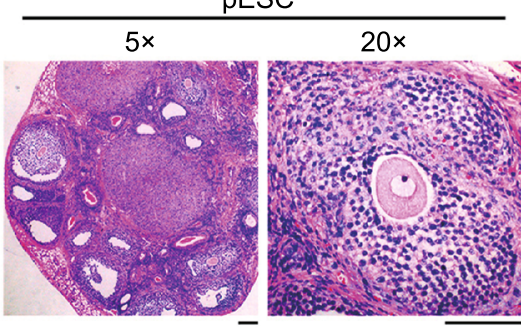

ESC

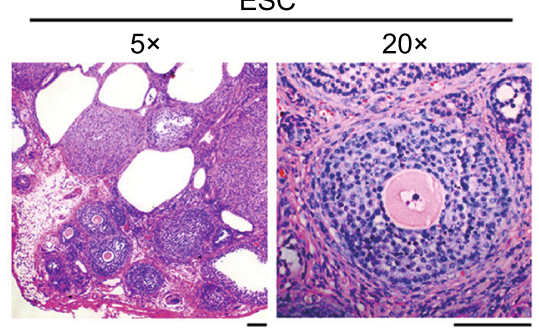

G
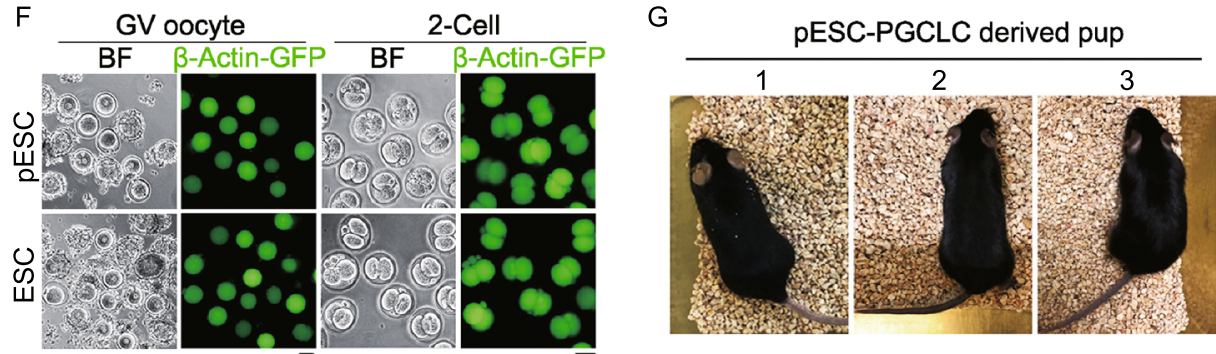

$\mathrm{J}$
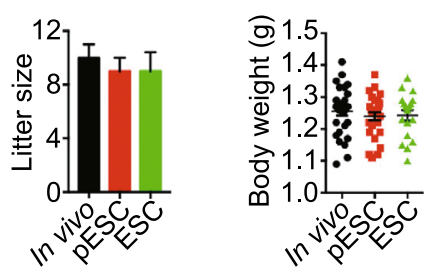

K

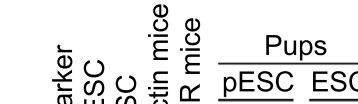

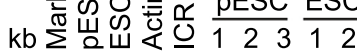

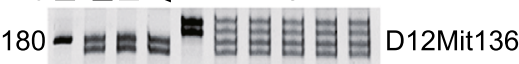

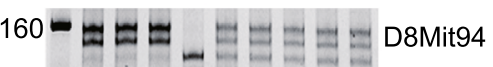

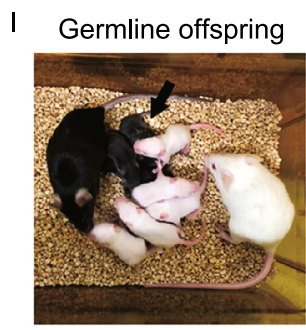

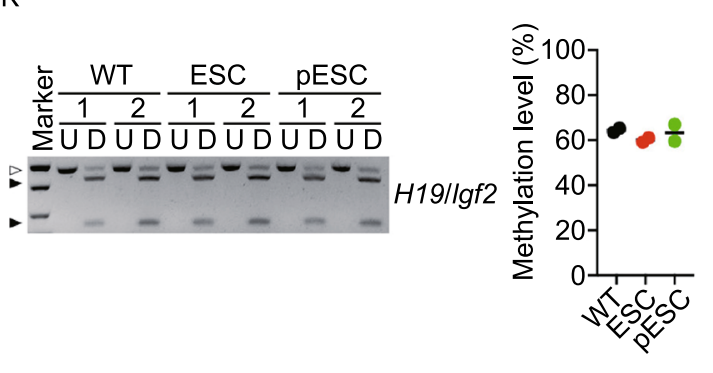
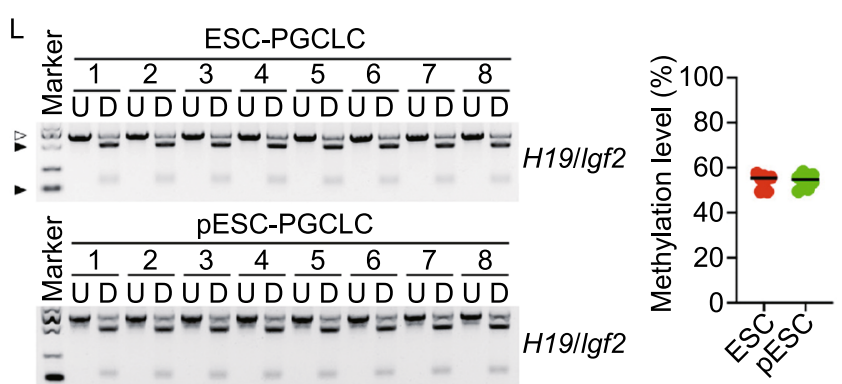
Figure 5. Fertile mice produced from oocytes of pESCs. (A) Normal synaptonemal complex in pESC-and ESC-derived meiocytes 5 days following transplantation of the PGCLCs aggregates based on pachytene spread by super high-resolution microscopy (SIM). Scale bar $=5 \mu \mathrm{m}$. (B) Statistics of MLH1 foci per cell at pachytene stage in meiocytes derived from pESC- or ESC-PGCLCs. Scale bar $=5 \mu \mathrm{m}$. (C) Morphology and Actin-GFP expression of reconstituted ovaries. Scale bar $=1$ $\mathrm{mm}$. (D) Folliculogenesis of pESC- and ESC-derived reconstituted ovaries by H\&E staining. Scale bar $=100 \mu \mathrm{m}$. (E) Follicle count of pESC- and ESC-reconstituted ovaries 28 days following transplantation of the aggregates into kidney capsule. Data shown as Mean \pm SEM $(n=4)$. ${ }^{*} P<0.05$. (F) GV oocytes isolated from pESC- and ESC-reconstituted ovaries, and 2-cell embryos after IVM and IVF. Scale bar $=50 \mu \mathrm{m}$. (G) Healthy adult mouse produced from pESC-PGCLCs derived oocytes following IVM and IVF. (H) Genotyping analysis of the pups by microsatellite primers D8mit94 and D12Mit136. DNA was isolated from tail tip tissues. (I) Offspring of pESC-PGCLCs derived mice by mating with albino ICR mice. $(J)$ Similar litter size and body weight of pups produced from oocytes of pESCs and ESCs in comparison with those of wild-type (/in vivo) mice served as a control. (K) Combined bisulfite restriction analysis (COBRA) of typical imprints H19/lgf2 of tail tissue from ESCand pESC-PGCLC derived mice $(n=2)$. Wild-type (WT) mice from normal breeding at the same background served as control. PCR products were either digested (D) or undigested $(U)$ with the respective enzyme. The digested and undigested fragments are indicated by black and white triangles, respectively. Right panel, Methylation level analysis of COBRA by Image J. (L) COBRA of typical imprints H19/lgf2 of the tail tissue from the offspring derived from ESC- and pESC-PGCLC derived mice $(n=8)$. Right panel, Methylation level analysis of COBRA by Image $\mathrm{J}(n=8)$.

\section{Oocytes regenerated from $\mathrm{pESCs}$ produce fertile offspring}

Moreover, we tested whether PGCLCs, differentiated from pESCs, can produce developmentally competent oocytes. Meiosis and oocyte growth were induced by aggregation of PGCLCs with fetal E12.5 gonadal somatic cells, including pre-granulosa cells, followed by transplantation of the aggregates into the kidney capsule, to form reconstituted ovaries (Shen et al. 2006; Qing et al. 2008). Rock inhibitor and Vitamin $\mathrm{C}$ were supplemented in the aggregation medium to improve follicular development of PGCLCs aggregated with fetal gonadal somatic cells (Tian et al. 2019). To evaluate meiotic progression of PGCLCs derived from pESCs, we analyzed homologous chromosome pairing and synapsis, by immunofluorescence microscopy of SCP $1 / 3$ elements, and recombination by MLH1, key events of meiotic prophase I (Handel et al. 2014). SCP1 and SCP3 together form an evolutionarily conserved protein structure, the synaptonemal complex (SC), located along the paired meiotic chromosomes, which plays an important role in meiosis (Yuan et al. 2000). MLH1 is a mismatch repair gene involved in meiotic crossing over and recombination (Baker et al. 1996; Edelmann et al. 1996). Aggregates were treated with $3 \mu \mathrm{mol} / \mathrm{L}$ retinoic acid (RA) for one day, then transplanted into kidney capsules of oophorectomized females for five days, to facilitate PGCLCs entry into meiosis, similar to meiocytes of E16.5-E17.5 female gonads. PGCLCs aggregated with E12.5 gonad somatic cells differentiated into meiocytes with discernible SCP3 elements, which indicate homologous pairing. In contrast, pseudo-aggregates formed from only E12.5 gonad somatic cells as negative controls, displayed only background staining of some green spots but no distinct SCP3 lateral elements (Fig. S5A). SCP1/3 stained the axial elements of synaptonemal complexes at leptotene, zygotene, pachytene, and diplotene stages of prophase $\mathrm{I}$, similar to that observed in ESC-PGCLCs (Figs. 5A and S5B). MLH1 foci appeared at crossover sites, with a frequency similar to E17.5 meiocytes and PGCLCs differentiated from ESCs (Fig. 5B). Hence, PGCLCs derived from $\mathrm{pESC}$ can undergo normal homologous pairing and recombination during meiotic progression.

To further validate the germ cell identity of PGCLCs originating from $\mathrm{pESCs}$, transplantation of aggregated PGCLCs into kidney capsules for 4 days revealed Actin-GFP fluorescence co-localized with cytoplasmic Dazl staining, typical germ cell marker (Fig. S6A). Twenty-eight days after transplantation of aggregates, Actin-GFP fluorescence within follicles was visible in reconstituted ovaries (Fig. 5C). Developing and mature follicles with germinal vesicle (GV) oocytes were observed in sections stained by H\&E (Fig. 5D). Immunofluorescence staining of oocytes for Vasa, Dazl and GFP, and granulosa cells for Foxl2 and Gata4 further confirmed the cellular identify of reconstituted ovaries (Fig. S6B). The number of total follicles did not differ between reconstituted ovaries formed from pESC- or ESC-PGCLCs, but reconstituted ovaries from $\mathrm{pESC}-\mathrm{PGCLCs}$ had more mature follicles than did ESC-PGCLCs (Fig. 5E).

We analyzed the function of reconstituted ovaries by measuring endocrine activity, including serum levels of follicle-stimulating hormone (FSH), estradiol (E2) and anti-Mullerian hormone (AMH) in the recipient NOD-SCID mice. The bilaterally oophorectomized (OE) mice, without receiving the ovarian grafts, served as negative controls. Serum FSH levels were reduced and $\mathrm{E} 2$ and $\mathrm{AMH}$ levels increased markedly in the $\mathrm{OE}$ recipients receiving the reconstituted ovarian grafts (Fig. S6C), indicating that PGCLCs derived from $\mathrm{pESCs}$, following aggregation with fetal gonadal somatic cells, develop into functional follicles in reconstituted ovaries with capacity to restore the hormone production and secretion. Because the germ cells and accompanied somatic cells interact and both are essential for follicle development (Buccione et al. 1990), both germ cells and somatic cells contributed to the endocrine function. Hence, the follicles of the reconstituted ovaries from germ cell-like cells differentiated from $\mathrm{pESC}$ s recovered the endocrine functions of 
ovariectomized mice, providing further evidence of the functionality of the germ-cell like cells and the derivedoocytes.

Furthermore, to test whether oocytes generated from pESCs can produce fertile pups, we mechanically dissected GV oocytes from follicles in reconstituted ovaries and performed in vitro maturation (IVM) and in vitro fertilization (IVF). PGCLCs-derived oocytes were able to reach MII stage, fertilize, and cleave to two-cell embryos (Fig. 5F). Efficiency of cleavage to two-cells after IVM and IVF of pESCPGCLCs-derived GV oocytes was $35.4 \%$ (64 two-cell embryos developed from IVM and fertilization of $181 \mathrm{GV}$ oocytes), an efficiency comparable to that of ESC-PGCLCs (52 two-cell embryos from $147 \mathrm{GV}$ oocytes) (Table S2). Three live pups were obtained following transfer of 64 twocell embryos developed from oocytes of pESC-PGCLCs (Fig. 5G). The efficiency of embryo development to term from pESC-PGCLCs approximated half of PGCs in vivo which we recently reported using the same aggregation and transplantation methods (Sheng et al. 2019) (also, Table S2). The origin of offspring from PGCLCs was further validated by strain-specific microsatellite marker assays of donor and recipient mice (Fig. $5 \mathrm{H}$ ). All mice survived and grew to healthy adulthood. Fertility and germline competence were normal in these animals (Fig. 5I). Litter size and body weight of offspring generated from oocytes of pESC-PGCLCderived mice did not differ from those produced by in vivo, natural breeding, or from ESC-PGCLC-derived mice (Fig. 5J). Tissue samples such as heart, liver, spleen and gonad obtained from ESC- and pESC-PGCLC derived mice as well as the gonad from the offspring derived from ESCand pESC-PGCLC derived mice expressed GFP fluorescence (Fig. S7A-C), further validating the origin of mice produced from donor ESCs/pESCs and their derived oocytes.

We also compared the imprinting status of mice produced from PGCLCs to that of normally bred mice. Methylation levels of the familiar imprinted genes, H19/lgf2, Snrpn, Igf2r, DIk1/Gt/2 and Mest, in PGCLC-derived mice and the gene expression levels did not differ from those of naturally bred, wild-type mice (Figs. 5K and S8A-C). Moreover, methylation levels of imprinted genes were comparable among secondgeneration pups (pups generated form PGCLC-derived mice after breeding) of pESC-PGCLCs and ESC-PGCLCs and normally bred mice (Figs. 5L, S8D and S8E). Together, PGCLCs differentiated from pESCs develop into fully functional oocytes and produce healthy, fertile offspring.

\section{DISCUSSION}

We show that differentiation of the pESCs derived from parthenogenetically activated oocytes provides an unlimited source of developmentally competent oocytes, capable of producing fertile mice. Transcriptome, methylome, and imprinting patterns of pESC-derived PGCLCs closely resemble those of ESC-derived PGCLCs as well as in vivo produced PGCs.

Efficiency of generating pESCs from activated oocytes with strontium varies among mouse strains, ranging from about $20 \%$ in inbred strains (e.g., C57BL/6), comparable to derivation of inbred ESCs (Nagy et al. 1993; Eggan et al. 2001), to about 30\% in hybrid strains. On the inbred C57BL/6 background, germline-competent pESC lines were obtained with stable XX chromosomes (Fig. S1B) from an average of one out of 16 oocytes. After expansion in culture for 10 passages, such one cell line could produce $2.4 \times 10^{6} \mathrm{GV}$ oocytes (Table S3). Recently, PGCLCs were successfully expanded in vitro to elevate their numbers (Ohta et al. 2017). BMP and retinoic acid synergistically induce PGCLCs derived from ESCs into fetal primary oocytes (Miyauchi et al. 2017). Vitamin C and Rock inhibitors promote aggregation, induction of meiosis, and oocyte and follicle development (Tian et al. 2019). Currently, the development and growth of pESC or ESC-derived PGCLCs as well as of PGCs in vivo following their transplantation are still limited. GV oocytes from pESCs and ESCs show similar maturation rate, but the efficiency of embryo development to term from pESCPGCLCs is about half of PGCs in vivo. Although overall expression levels of maternal and paternal genes do not differ significantly between pESC-PGCLCs and ESCPGCLCs and they also exhibit similar high rates of X-chromosome activation, subtle differences do exist in specific transcriptome and methylation between PGCLCs differentiated from pESCs or ESCs and PGCs in vivo. Future experiments must resolve these issues and increase the number of viable embryos available from PGCLCs or PGCs. Nevertheless, these oocytes can contribute to folliculogenesis and reconstitute endocrine function.

PGCLCs also have been successfully induced from human ESCs and iPSCs (Irie et al. 2015; Sasaki et al. 2015), and these hESCs/hiPSCs-derived PGCLCs can differentiate into oogonia (Yamashiro et al. 2018). Generation of oocytes in vitro from human PSCs has yet to be achieved. Additionally, a number of patients undergo failed embryonic development in clinical recurrent IVF/ICSI, because of defective maturation of GV oocytes. But parthenogenetic embryonic stem cells require matured oocytes, limiting pESC derivation in these patients. Encouragingly, human pESCs also have been derived by simple methods using chemical activation of oocytes. Human pESCs show epigenetic changes in imprinted genes compared with hESCs, including $X$ chromosome activation, imprinted DMRs, distinct imprinting signatures and biased differentiation (Kim et al. 2007; Lin et al. 2007; Mai et al. 2007; Revazova et al. 2007; Stelzer et al. 2013; Sagi et al. 2016, 2019). Our data that PGCLCs differentiated from pESCs develop into fully functional oocytes and produce healthy, fertile mice with normal imprinting provides proof of principle, suggesting that it is also possible to generate oocytes from human pESCs and used for reconstructing ovarian functions. However, the safety on corresponding metabolic and development 
phenotypes of live pups needs to be critically evaluated in future experiments. Also, extensive research is needed to ensure that PGCLCs generated from pESCs resemble PGCs in vivo at molecular levels and the competent embryo development like that of IVF from normal oocytes. Clearly, additional work will be needed to extend our findings to humans. If successful in humans, this approach could amplify the severely limited stores of a woman's oocytes, to potentially recover endocrine functions with age, and to produce autologous pluripotent stem cells essential for regenerative medicine. This strategy also may provide a technical advance to the ESC field by producing an unlimited number of oocytes for nuclear transfer ESCs.

\section{MATERIALS AND METHODS}

Animal care and use

Use of mice for this research was approved by the Nankai University Animal Care and Use Committee. All mice used in this study were taken care of and operated according to the relevant regulations. Mice were housed and cared in individually ventilated cages (IVCs) on a standard $12 \mathrm{~h}$ light: $12 \mathrm{~h}$ dark cycle in the sterile Animal Facility at College of Life Sciences. C57BL/6-Tg (CAG-EGFP) C14-Y01FM131Osb mice that carry $\beta$-Actin-GFP and Oct4-GFP (OG2) mice (C57BL6 X CBA) were obtained from Model Animal Research Center of Nanjing University. It was anticipated that Actin-GFP fluorescence could facilitate identification of transplant cells in transplantation experiments. 4-6-Week-old NOD-SCID mice (Female, \#406), 6-week-old albino Balb/c mice (Female, \#401), 6-8-week-old albino ICR mice (Male and female, \#201) and 6-week-old albino Kunming (KM) mice (Female, \#202) were purchased from Beijing Vital River Laboratory Animal Technology Co., Ltd.

\section{Isolation and primary cultured MEFs}

MEFs were derived from E13.5 ICR mice embryos isolated by caesarean section and washed in phosphate-buffered saline (PBS). Heads and visceral tissues were removed, and remaining tissue washed in PBS, then submerged in $0.25 \%$ trypsin-EDTA $0.25 \%$ TE, Invitrogen) and incubated at $37^{\circ} \mathrm{C}$ for $10 \mathrm{~min}$. Tissue was pipetted repeatedly to aid dissociation, washed then dissociated cells added to MEF medium and plated (passage $0, P 0$ ). MEF medium contains DMEM (Invitrogen) supplemented with 10\% Fetal Bovine Serum (FBS, Hyclone), $1 \mathrm{mmol} / \mathrm{L}$ L-glutamine (Invitrogen), $1 \%$ nonessential amino acid stock (NEAA, Sigma), and 50 units $/ \mathrm{mL}$ penicillin and 50 $\mu \mathrm{g} / \mathrm{mL}$ streptomycin (Invitrogen).

\section{Establishment of mouse pESC and ESC lines}

Actin-GFP female mice at 6-8 weeks of age were superovulated with $5 \mathrm{IU}$ pregnant mare serum gonadotrophin (PMSG), followed by 5 IU human chorionic gonadotropin (hCG) 46-48 h later. Oocytes enclosed in cumulus masses were collected from oviduct ampullae $14 \mathrm{~h}$ after hCG injection. In vitro maturation of GV oocytes $46 \mathrm{~h}$ following PMSG injection was achieved by culture in IVM medium following the method described (Eppig et al. 2009). Cumulus cells of MII oocytes were removed by pipetting, after a brief incubation in
$0.03 \%$ hyaluronidase prepared in potassium simplex optimized medium $\left(\mathrm{KSOM}_{\mathrm{AA}}\right)$ containing $14 \mathrm{mmol} / \mathrm{L}$ HEPES and $4 \mathrm{mmol} / \mathrm{L}$ sodium bicarbonate (HKSOM). Oocytes were reliably activated by treatment for $4 \mathrm{~h}$ with $10 \mathrm{mmol} / \mathrm{L} \mathrm{SrCl}_{2}$ and cytochalasin D prepared in $\mathrm{Ca}^{2+}{ }^{2}$ free KSOM (Chen et al. 2009; Liu et al. 2011). Activated oocytes with two pronuclei were defined as diploid parthenotes and cultured in $50 \mu \mathrm{L}$ droplets of pre-equilibrated $\mathrm{KSOM}$, covered with mineral oil at $37{ }^{\circ} \mathrm{C}$ in a humidified atmosphere of $6 \% \mathrm{CO}_{2}$ in air for 4-5 days. To obtain fertilized embryos, Actin-GFP females were superovulated and mated individually with Actin-GFP males of proven fertility. Oviducts of successfully mated females 3.5 days after mating were flushed with HKSOM using a Pasteur pipette, and blastocysts were obtained to derive normal ESC lines.

pESC and ESC lines were established and characterized in collaboration with $\mathrm{D}$. Keefe based on the method described (Chen et al. 2009; Liu et al. 2011). Blastocysts were plated onto mitomycin C-treated MEF cells served as feeders in KSR/DMEM medium plus PD0325901 and LIF (K/DL) and cultured for 7 days to form outgrowths. Emerging ICM outgrowths were directly picked and placed onto feeder cells in serum/LIF (S/L) medium to establish stable ESC lines. Established ESC lines were genotyped by Sry gene to determine the sex. Female ESC lines were also maintained in serum/LIF (S/L) medium and passaged by dissociating cells with $0.25 \%$ TE (Invitrogen) every 2-3 days and re-plated onto feeder cells. K/DL medium contains knockout DMEM (Invitrogen) supplemented with $20 \%$ Knockout serum replacement (KSR, Invitrogen), $1 \mathrm{mmol} / \mathrm{L}$ L-glutamine, $1 \%$ nonessential amino acid stock, 50 units/ $\mathrm{mL}$ penicillin and $50 \mu \mathrm{g} / \mathrm{mL}$ streptomycin (Invitrogen), $0.1 \mathrm{mmol} / \mathrm{L}$ $\beta$-mercaptoethanol (Invitrogen), $1 \mu \mathrm{mol} / \mathrm{L}$ PD0325901 (Miltenyi) and $1000 \mathrm{IU} / \mathrm{mL}$ mouse LIF (mLIF, Millipore). S/L medium (ESC culture medium) contains knockout DMEM supplemented with 15\% FBS (ES quality, Hyclone), $1 \mathrm{mmol} / \mathrm{L}$ L-glutamine, $1 \%$ nonessential amino acid stock, 50 units $/ \mathrm{mL}$ penicillin and $50 \mu \mathrm{g} / \mathrm{mL}$ streptomycin, $0.1 \mathrm{mmol} / \mathrm{L} \beta$-mercaptoethanol, and $1000 \mathrm{IU} / \mathrm{mL} \mathrm{mLIF}$.

\section{Karyotype analysis}

Metaphase chromosomes were prepared by exposing cultured cells to nocodazole $(0.3 \mu \mathrm{g} / \mathrm{mL})$ for $3 \mathrm{~h}$, followed by hypotonic treatment with $75 \mathrm{mmol} / \mathrm{L} \mathrm{KCl}$ solution, fixed with methanol:glacial acetic acid (3:1) and spread onto clean slides under humidified cold environment. About 30 separate metaphase spreads were examined for each culture.

\section{Induction of PGC-like cells (PGCLCs)}

Induction of PGCLCs from pESCs/ESCs was based on the method described previously (Hayashi et al. 2012; Hayashi and Saitou 2013). ESCs and pESCs were maintained in t2iL medium (in 2iL medium, the concentration of PD0325901 was reduced from $1 \mu \mathrm{mol} /$ $L$ to $0.4 \mu \mathrm{mol} / \mathrm{L}$ ) for $3-5$ passages. EpiLCs were induced by plating $1.0 \times 10^{5} \mathrm{pESCs} / \mathrm{ESCs}$ on the wells of a 12-well plate coated with human plasma fibronectin ( $\mathrm{FN}, 16.7 \mu \mathrm{g} / \mathrm{mL}$, Millipore) in N2B27 medium containing activin A (20 ng/mL, PeproTech), bFGF (12 ng/ $\mathrm{mL}$ ), and $1 \% \mathrm{KSR}$ for $46 \mathrm{~h}$. The medium was changed every day. The PGCLCs were induced for 4 days under floating conditions by plating $3.0 \times 10^{3}$ EpiLCs in the wells of a low-cell-binding U-bottom 96-well Lipidure-Coat plate (Corning) in GK15 medium (GK15 
medium contains GMEM (Invitrogen) added with 15\% KSR, $100 \mu \mathrm{mol} / \mathrm{L} \mathrm{NEAA}, 1 \mathrm{mmol} / \mathrm{L}$ sodium pyruvate, $1 \mathrm{mmol} / \mathrm{L}$ L-glutamine, $1 \%$ nonessential amino acid stock, $50 \mathrm{units} / \mathrm{mL}$ penicillin and $50 \mu \mathrm{g} / \mathrm{mL}$ streptomycin, $0.1 \mathrm{mmol} / \mathrm{L} \beta$-mercaptoethanol) in the presence of the cytokines BMP4 (500 ng/mL, PeproTech), $1000 \mathrm{IU} / \mathrm{mL} \mathrm{mLIF}, \mathrm{SCF}$ (100 ng/mL, PeproTech) and EGF (50 ng/mL, PeproTech). Integrin$\beta 3-$ (CD61) and SSEA1-double positive PGCLCs were sorted by flow cytometer. Dissociated cells were incubated with anti-integrin- $\beta 3$ (CD61) antibody and anti-SSEA1 antibody conjugated with PE (Phycoerythrin) and APC (Allophycocyanin), respectively. After being washed in PBS supplemented with $0.1 \%$ BSA, the cells were sorted and analyzed on a flow cytometer (Aria III; BD Biosciences).

Induction of meiosis and folliculogenesis

IInduction of meiosis and folliculogenesis was achieved by aggregation of PGCLCs with E12.5 gonadal somatic cells followed by transplantation of the aggregates into kidney capsules to generate reconstituted ovaries (Qing et al. 2008). To obtain E12.5 gonad somatic cells in vivo, female E12.5 gonads were collected from E12.5 embryos obtained by intercrosses of albino ICR mice. The mesonephros were surgically separated from the gonads using insulin syringe. Gonads were dissociated with $0.05 \%$ TE by incubation at $37^{\circ} \mathrm{C}$ for $10 \mathrm{~min}$, washed with MEF medium, and collected by centrifugation. Large clumps of cells were removed using a cell strainer (BD Biosciences). Endogenous PGCs in the dissociated gonadal cells were removed or collected by magnetic cell sorting using anti-SSEA1 antibody conjugated with magnetic beads (Miltenyi, see below). The sorted gonadal somatic cells and FACS-sorted PGCLCs were plated in the wells of a low-cell-binding U-bottom 96-well Lipidure-Coat plate in MF10 medium (MF10 medium contains M199 (Sigma) added with $10 \%$ FBS, $1 \mathrm{mmol} / \mathrm{L}$ L-glutamine, 50 units $/ \mathrm{mL}$ penicillin and $50 \mu \mathrm{g} / \mathrm{mL}$ streptomycin, $50 \mu \mathrm{g} / \mathrm{mL}$ Vitamin C (Vc, Sigma) and $10 \mu \mathrm{mol} / \mathrm{L}$ Rocki (Y27632, Rock inhibitor) (Tian et al. 2019). About 20,000 PGCLCs and 100,000 gonadal somatic cells were mixed per aggregate. For negative control (pseudo-rOvary), 100,000 E12.5 gonadal somatic cells only without PGCs were aggregated in MF10 medium supplemented with $50 \mu \mathrm{g} / \mathrm{mL} V_{c}$ and $10 \mu \mathrm{mol} / \mathrm{L}$ Rocki.

\section{Magnetic activated cell sorting}

Magnetic activated cell sorting (MACS) was performed according to the manufacturer's instructions (Miltenyi). Briefly, dissociated gonadal cells were incubated with anti-SSEA1 antibody conjugated with magnetic beads. Cell suspensions were washed in PBS supplemented with $0.5 \%$ BSA and $2 \mathrm{mmol} / \mathrm{L}$ EDTA and applied to an MS column (Miltenyi) to remove SSEA1-positive PGCs. Gonadal somatic cells were collected in the flow-through portions. To verify that SSEA1 negative cells did not contain PGCs, SSEA1/CD61 double staining was used to detect PGCs by FACS. More than 99.99\% cells did not express SSEA1 and CD61, showing the purity of embryonic gonadal somatic cells.

\section{Isolation of E9.5 and E12.5 PGCs}

Embryonic gonads were dissected from E9.5 and E12.5 female embryos. Gonads were dissociated by $0.25 \%$ TE (Invitrogen), and filtered by $70 \mu \mathrm{m}$ cell Filter, followed by sorting of PGCs by flow cytometer using anti-integrin- $\beta 3$ (CD61) antibody and anti-SSEA1 antibody or MACS using anti-SSEA1 antibody conjugated with magnetic beads.

\section{Kidney capsule transplantation}

Kidney capsule transplantation was performed based on the methods described (Qing et al. 2008). Briefly, one or two aggregates were implanted in the "pocket" which was made between the kidney capsule and kidney tissue of a bilaterally ovariectomized recipient mouse. Transplantation procedure was completed in $5 \mathrm{~min}$ for each mouse. Meiosis and folliculogenesis were achieved in the reconstituted ovaries 26-28 days following transplantation of the aggregates.

\section{Follicle count}

The aggregate-formed reconstituted ovaries were carefully retrieved and subsequently dehydrated with graded alcohols, cleared in xylene, and embedded in paraffin wax. The serial sections $(5 \mu \mathrm{m})$ from each reconstituted ovary were aligned in order on glass microscope slides, stained with H\&E and analyzed for the number of follicles at various developmental stages in every fifth section with random start in the first five sections. The total number of follicles per reconstituted ovary was calculated by combining the counts of every fifth section throughout the whole reconstituted ovary, based on method described (Liu et al. 2013). The follicles were categorized into, secondary and antral or mature accordingly. Secondary follicles were characterized as having more than one layer of GCs with no visible antrum. Antral or mature follicles possessed small areas of follicular fluid (antrum) or a single large antral space. Only those follicles containing an oocyte with a clearly visible nucleus were scored.

\section{In vitro maturation and in vitro fertilization}

The reconstituted ovaries were dissected from the recipient mouse kidney capsule, and fully-grown GV oocytes were collected under a microscope by pricking follicles using insulin syringe in in vitro maturation (IVM) medium. Oocytes were matured in vitro by culture in IVM medium for $17-18 \mathrm{~h}$ at $37^{\circ} \mathrm{C}$ (Eppig et al. 2009). IVM medium contained $\alpha$-MEM (Invitrogen) added with 5\% FBS, $0.24 \mathrm{mmol} / \mathrm{L}$ sodium pyruvate, $1 \mathrm{IU} / \mathrm{mL}$ PMSG and $1.5 \mathrm{IU} / \mathrm{mL} \mathrm{hCG}$. With this IVM method, $80 \%$ of maturation rate was routinely obtained for oocytes collected in vivo.

For in vitro fertilization (IVF), spermatozoa were collected from the cauda epididymis of albino ICR males, capacitated by incubation for $2 \mathrm{~h}$ in HTF (Origio), and then incubated with the matured oocytes for $6 \mathrm{~h}$. The zygotes were transferred into human G-1 plus medium (Vitrolife). Embryos that reached the 2-cell stage after $24 \mathrm{~h}$ culture were transferred into the oviducts of E0.5 pseudo pregnant mice (albino Kunming mice) and newborns were normally delivered on E19.5. Pups were identified initially by coat color. The contribution of pESCs and ESCs of pups was confirmed by standard DNA microsatellite genotyping analysis using D8Mit94 and D12Mit136 primers (Table S4). 
Test of developmental pluripotency by generation of chimeras

Approximately 10-15 pESCs or ESCs were injected into 4-8-cell embryos of albino not Balb/c as hosts using a Piezo injector as described (Huang et al. 2008). Injected embryos were cultured overnight in $\mathrm{KSOM}_{\mathrm{AA}}$ medium. Blastocysts were transferred into uterine horns of E2.5 surrogate albino Kunming mice. Pregnant females delivered pups naturally at about E19.5. Pups were identified initially by coat color. Chimeras were mated with albino ICR mice to further examine their germline transmission competence.

\section{Immunofluorescence microscopy}

Cells were washed twice in PBS, fixed in freshly prepared $3.7 \%$ paraformaldehyde for $30 \mathrm{~min}$ on ice, washed once in PBS and permeabilized in $0.1 \%$ Triton $\mathrm{X}-100$ in blocking solution (3\% goat serum plus $0.1 \% \mathrm{BSA}$ in PBS) for $30 \mathrm{~min}$ at room temperature, then washed three times in PBS, and left in blocking solution for $2 \mathrm{~h}$. Cells were incubated overnight at $4{ }^{\circ} \mathrm{C}$ with primary antibodies, anti-Oct4 and anti-Nanog prepared in blocking solution, washed three times for $15 \mathrm{~min}$ each with blocking solution, followed by incubation for $2 \mathrm{~h}$ with secondary antibodies at room temperature. Alexa Fluor ${ }^{\circledR} 594$ goat anti-mouse $\operatorname{lgG}(\mathrm{H}+\mathrm{L})$ against anti-Oct4 or Alexa Fluor ${ }^{\circledR} 594$ goat anti-rabbit $\lg G(\mathrm{H}+\mathrm{L})$ against anti-Nanog diluted in 1:200 with blocking solution was used. Samples were washed, and counterstained with $0.5 \mu \mathrm{g} / \mathrm{mL}$ DAPI (Roche) in Vectashield (Vector) mounting medium. Fluorescence was detected and imaged using Axio-Imager Z2 Fluorescence Microscope (Carl Zeiss).

\section{Fluorescence microscopy of reconstituted ovarian sections}

Briefly, after being deparaffinized, rehydration and wash in $0.01 \mathrm{~mol} / \mathrm{L}$ PBS ( $\mathrm{pH} 7.2$ ), sections were subjected to high pressure antigen recovery sequentially in $0.01 \mathrm{~mol} / \mathrm{L}$ citrate buffer $(\mathrm{pH} 6.0)$ for $3 \mathrm{~min}$, so that the autofluorescence of Actin-GFP was quenched. The sections were incubated with blocking solution ( $3 \%$ BSA in PBS) for $2 \mathrm{~h}$ at room temperature, and then with the diluted primary antibodies overnight at $4{ }^{\circ} \mathrm{C}$. The primary antibodies included anti-SCP3, GFP, Vasa, Dazl, Foxl2, or Gata4 prepared in blocking solution. Blocking solution without the primary antibody served as negative control. After washing with PBS three times, sections were incubated with appropriate secondary antibodies, AlexaFluor 894 Donkey anti-Goat IgG (Foxl2), AlexaFluor ${ }^{\circledR} 594$ Goat Anti-Mouse lgG (Gata4), AlexaFluor ${ }^{\circledR}$ 488 Donkey anti-Mouse IgG (GFP), AlexaFluor ${ }^{\circledR} 488$ Donkey antiRabbit IgG (SCP3, Vasa, and Dazl) or AlexaFluor® 594 Goat AntiRabbit IgG (Dazl in the sections of day 4 reconstituted ovaries). Nuclei were stained with $0.5 \mu \mathrm{g} / \mathrm{mL}$ DAPI in Vectashield mounting medium. Fluorescence was detected and imaged using Axio-Imager Z2 Fluorescence Microscope (Carl Zeiss).

Immunostaining and fluorescence microscopy of meiocyte spreads

Surface spreading of meiocytes was prepared by a drying-down technique and stained for synaptonemal complexes (Liu et al. 2004). PGCLC-aggregates were collected, minced with two forceps and dissociated by pipetting in $0.05 \%$ TE. After incubation for $7 \mathrm{~min}$ at $37{ }^{\circ} \mathrm{C}$, cell suspensions were mixed with an equal volume of FBS, centrifuged for $5 \mathrm{~min}$ and resuspended in $100 \mathrm{mmol} / \mathrm{L}$ sucrose. The cell suspension was spread onto glass slide by dipping onto a thin layer of fixative ( $1 \%$ paraformaldehyde, $0.15 \%$ Triton X-100 and 3 $\mathrm{mmol} / \mathrm{L}$ dithiothreitol, $\mathrm{pH}$ 9.2). The glass slides were maintained overnight in a humidified box at $4{ }^{\circ} \mathrm{C}$. The slides were washed in water containing $0.4 \%$ Photo-flow (Kodak), and completely dried at room temperature. Dried slides were washed with $0.1 \%$ Triton $X-100 / P B S$ (PBST) for 10 min and incubated with antibody dilution buffer (ADB) (3\% BSA and $2 \%$ goat serum in PBST) for $1 \mathrm{~h}$ at room temperature. Spreads were then incubated with anti-SCP1, SCP3 or $\mathrm{MLH} 1$ antibody in ADB at $4{ }^{\circ} \mathrm{C}$ overnight, washed three times, then incubated with appropriate secondary antibodies, AlexaFluor ${ }^{\circledR} 488$ Goat anti-Rabbit IgG or AlexaFluor ${ }^{\circledR} 594$ Goat anti-Rabbit IgG (SCP3), FITC Goat anti-Mouse IgG $(\mathrm{H}+\mathrm{L})(\mathrm{MLH} 1)$ and AlexaFluor $\circledast$ 594 Goat anti-Mouse IgG (SCP1). After washing, samples were stained with DAPI, washed and mounted in Vectashield mounting medium (Vector Laboratories). Immunofluorescence was detected using Axio-Imager Z2 Fluorescence Microscope. MLH1 foci were counted as described (Liu et al. 2004). Autofluorescence of ActinGFP was not observed in these spreads.

\section{Hormone assays}

Serum follicle-stimulating hormone (FSH), estradiol (E2) and antiMüllerian hormone $(\mathrm{AMH})$ levels were assayed by ELISA kit (CKE20381, CK-E20419 and CK-E90200, Hangzhou EastBiopharm CO., LTD). Quality control serum, sterilized distilled water, and five series diluted standard samples for a standard curve were tested for each serum sample. The intra- and inter-assay coefficients of variability for $\mathrm{AMH}, \mathrm{FSH}$, and $\mathrm{E} 2$ were below $8 \%$ and $12 \%$.

\section{Gene expression analysis by real-time qPCR}

Total RNA was purified using RNA mini kit (QIAGEN), treated with DNase I (QIAGEN), and the cDNA was generated from $2 \mu \mathrm{g}$ RNA using Oligo (dT)18 primer (Takara) and M-MLV Reverse Transcriptase (Invitrogen). Real-Time qPCR reactions were set up in duplicate with the FS Universal SYBR Green Master (Roche) and carried out on an iCycler MyiQ2 Detection System (Bio-Rad). All reactions were carried out by amplifying target genes and internal control in the same plate. Each sample was repeated two times and normalized using Gapdh as the internal control. The amplification was performed for primary denaturation at $95{ }^{\circ} \mathrm{C}$ for $10 \mathrm{~min}$, then 40 cycles of denaturation at $95^{\circ} \mathrm{C}$ for $15 \mathrm{~s}$, annealing and elongation at $58^{\circ} \mathrm{C}$ for $1 \mathrm{~min}$, and the last cycle under $55-95^{\circ} \mathrm{C}$ for dissociation curve. Relative quantitative evaluation of target gene was determined by comparing the threshold cycles. Primers (Table S5) were confirmed for their specificity with dissociation curves.

\section{Combined bisulfite restriction analysis (COBRA)}

COBRA analysis was performed based on the methods as described (Hikabe et al. 2016). Genomic DNA was extracted using DNeasy Tissue Kit (QIAGEN) according to the manufacturer's instructions. Bisulfite treatment of DNA was performed with the EpiTect Bisulfite Kit (QIAGEN). Bisulfite converted DNA was amplified by PCR, using HS Taq DNA Polymerase (QIAGEN) and primers (Table S6). Thermal cycling was carried out with a 10 min denaturation step at $94{ }^{\circ} \mathrm{C}$, followed by 35 three-step cycles $\left(30\right.$ s at $94{ }^{\circ} \mathrm{C}$, 
$30 \mathrm{~s}$ at $55-58{ }^{\circ} \mathrm{C}$ and $30 \mathrm{~s}$ at $72{ }^{\circ} \mathrm{C}$ ) and final incubation at $72{ }^{\circ} \mathrm{C}$ for $10 \mathrm{~min}$. PCR products were recovered from stained gels (Gel Extraction Kit, Transgene). The amplified DNA was digested with the following restriction enzymes (NEB): Acil for Snrpn and Igf2r, PvulHF for Dlk1/Glt2; HpyCH4IV for H19/lgf2r and Mest1. The digested samples were resolved through electrophoresis in $1.5 \%$ agarose gels and illuminated by GelRed (BioSharp).

\section{Library preparation and RNA-sequencing}

1000 Cells per sample were resuspended in PBS with $0.1 \%$ BSA and transferred to the bottom of a PCR tube consisting of $3 \mu \mathrm{L}$ lysis buffer, and cDNA was synthesized in the tube containing mRNA, based on Smart-seq2 protocol (Picelli et al. 2014), and the libraries were prepared using TruePrep DNA Library Prep Kit V2 for Illumina ${ }^{\circledR}$ (TD503-02, Vazyme Biotech) according to the manual instruction. Samples were barcoded and multiplex sequenced with a 150-bp paired-end sequencing strategy on an Illumina Hiseq platform.

Library preparation and reduced representation bisulfite sequencing (RRBS)

Cells were collected and isolated their genomic DNA by QIAamp DNA Micro Kit (QIAGEN). DNA purity was checked using the NanoPhotometer ${ }^{\circledR}$ spectrophotometer (IMPLEN, CA, USA) and DNA concentration was measured using Qubit ${ }^{\circ}$ DNA Assay Kit in Qubit ${ }^{\circ}$ 2.0 Flurometer (Life Technologies, CA, USA). A total amount of $1.5 \mu \mathrm{g}$ DNA spiked with moderate lambda DNA was handled by Mspl, followed by end repair and adenylation. Cytosine-methylated barcodes were ligated to sonicated DNA following manufacturer's instructions. The DNA fragments were treated twice with bisulfite using EZ DNA Methylation-GoldTM Kit (Zymo Research), and the resulting single-strand DNA fragments were PCR amplified using KAPA HiFi HotStart Uracil and ReadyMix (2X). Library concentration was quantified by Qubit $\circledast 2$ 2.0 Flurometer and quantitative PCR, and the insert size was assayed on Agilent Bioanalyzer 2100 system. The library preparations were sequenced on an Illumina Novaseq platform and $125 \mathrm{bp} / 150 \mathrm{bp}$ paired-end reads generated. Image analysis and base calling were performed with Illumina CASAVA pipeline.

Bismark software (version 0.16.3) was used to perform alignments of bisulfite-treated reads to a reference genome. The reference genome was firstly transformed into bisulfite-converted version (C-to-T and G-to-A converted) and then indexed using bowtie2. Sequence reads were also transformed into fully bisulfite-converted versions ( $\mathrm{C}$-to-T and G-to-A converted) before they were aligned to similarly converted versions of the genome in a directional manner. Sequence reads that produced a unique best alignment from the two alignment processes (original top and bottom strand) were then compared to the normal genomic sequence and the methylation state of all cytosine positions in the read was inferred. The same reads that were aligned to the same regions of genome were regarded as duplicates. The sequencing depth and coverage were summarized using duplicated reads. Results of methylation extractor were transformed into bigWig format for visualization using IGV browser. Sodium bisulfite non-conversion rate was calculated as the percentage of cytosine sequenced at cytosine reference positions in the genome.

\section{Bioinformatics analysis}

For RNA-seq, clean reads were mapped to the mouse reference mm10 reference genome using Hisat2. Reads were assigned and counted to genes using the Feature-counts. The resulting matrix of read counts was then loaded into RStudio ( $R$ version 3.4.2), and DESeq2 used to identify differentially expressed genes. Functional enrichment (GO annotation or KEGG) of gene sets with different expression patterns was performed using clusterProfiler. The heatmaps were drawn by the function "pheatmap" of R packages and correlation coefficients calculated by the function "cor" in R. Scatter plots were generated using the "ggplot2" package to graphically reveal genes that differ significantly between two samples. The $P$ values were adjusted using the Benjamin and Hochberg method (Hochberg and Benjamini 1990). Corrected $P$-value of 0.05 and twofold changes were set as the threshold for significantly differential gene expression. The PGC marker gene list was obtained based on previous published RNA-seq data (Miyauchi et al. 2017). Calculated Zscore, $\log _{10}(T P M), \log _{10}(T P M+1)$ or $\log _{2}(T P M+1)$ of selected genes was used for heatmap.

For RRBS, we modeled the sum Mc of methylated counts as a binomial (Bin) random variable with methylation rate $r$ to identify the methylation site. In order to calculate the methylation level of the sequence, we divided the sequence into multiple bins, with bin size at $10 \mathrm{~kb}$. The sum of methylated and unmethylated read counts in each bin were calculated. Methylation level (ML) for each bin or $C$ site shows the fraction of methylated $C$, and is defined as: $M L(C)=$ $\operatorname{reads}(\mathrm{mC}) /[(\operatorname{reads}(\mathrm{mC})+\operatorname{reads}(\mathrm{C}))$. Calculated $\mathrm{ML}$ was further corrected with the bisulfite non-conversion rate by: $\mathrm{ML}$ (corrected) $=$ $(\mathrm{ML}-\mathrm{r}) /(1-r)$. Analysis of fraction of $C p G s$ in global methylation levels and methylation heatmap for various genomic features were based on published methods (Seisenberger et al. 2012; Wang et al. 2014). Analysis of DNA methylation levels of maternal and paternal imprints was based on the published gene list (Xie et al. 2012; Li et al. 2016).

\section{Quantification and statistical analysis}

Statistics were analyzed by using the StatView software from SAS Institute, Inc. (Cary, NC). Data were analyzed using two-tailed unpaired Student's $t$ test to compare two groups or ANOVA to compare more than two groups and expressed as mean \pm SEM. $p$ values less than 0.05 were considered significant $\left({ }^{*} P<0.05,{ }^{* *} P<\right.$ 0.01 or $\left.{ }^{* * *} P<0.001\right)$. The exact values of " $n$ " used are described in the corresponding figure legends. " $n$ " refers to the number of biological replicates and includes either number of mice or replicates of cell studies. FACS data was analyzed by FlowJo. Graphs were generated using GraphPad Prism or R package ggplot2 or other $\mathrm{R}$ packages.

\section{ABBREVIATIONS}

$\mathrm{AMH}$, anti-Müllerian hormone; DMR, differentially methylated region; E2, estradiol; EB, embryoid body; EpiLCs, epiblast-like cells; ESC, embryonic stem cell; FACS, fluorescence-activated cell sorting; 
$\mathrm{FSH}$, follicle-stimulating hormone; GFP, green fluorescence protein; $\mathrm{GO}$, gene ontology; GV, germinal vesicle; H\&E, hematoxylin and eosin stain; ICSI, intracytoplasmic sperm injection; iPSC, induced pluripotent stem cell; IVF, in vitro fertilization; IVM, in vitro maturation; NOD-SCID mice, non-obese diabetic-server combined immune-deficiency mice; OE, bilaterally oophorectomized; PCA, principal components analysis; pESC, parthenogenetic embryonic stem cell; PGC, primordial germ cell; PGCLC, primordial germ celllike cell; RA, retinoic acid; RRBS, reduced representation bisulfite sequencing; SC, synaptonemal complex.

\section{ACKNOWLEDGMENTS}

We thank Huasong Wang, Kairang Jin, Guofeng Feng, Peng Gong, Jiao Yang and Yifei Liu for assisting the experiments and discussion, and Beijing Novogene Bioinformatics Technology Co., Ltd. for their RRBS services.

\section{DECLARATIONS}

\section{FUNDING}

This work was supported by China National Key R\&D Program (2018YFC1003004, 2018YFA0107002) and the National Natural Science Foundation of China (31430052, 91749129), as well as the Stanley H. Kaplan Research Fund at NYU School of Medicine.

\section{CONFLICT OF INTEREST}

The authors declare that they have no competing interests.

\section{ETHICAL APPROVAL}

All institutional and national guidelines for the care and use of laboratory animals were followed.

\section{DATA AVAILABILITY}

The accession number for RNA sequencing data reported in this paper is NCBI GEO: GSE141103 and GSE154144, and RRBS data is NCBI GEO: GSE153979. Information on oligonucleotide sequences can be found in the Tables S4, S5 and S6. Other relevant data and reagents that support the findings of this study are available from the corresponding author on reasonable request. Additional data related to this paper may be requested from the authors.

\section{CODE AVAILABILITY}

All the custom codes written in $\mathrm{R}$ is available from the corresponding authors upon reasonable request.

\section{AUTHOR CONTRIBUTIONS}

CLT, LLL and MZ performed experiments and analyzed the data. CLT wrote the manuscript. DH, XYS, LLW and XY helped the experiments. DLK provided reagents/materials (oocyte activation reagents and embryo culture media), discussed the project and revised the manuscript. LL conceived the project and revised the manuscript.

\section{OPEN ACCESS}

This article is licensed under a Creative Commons Attribution 4.0 International License, which permits use, sharing, adaptation, distribution and reproduction in any medium or format, as long as you give appropriate credit to the original author(s) and the source, provide a link to the Creative Commons licence, and indicate if changes were made. The images or other third party material in this article are included in the article's Creative Commons licence, unless indicated otherwise in a credit line to the material. If material is not included in the article's Creative Commons licence and your intended use is not permitted by statutory regulation or exceeds the permitted use, you will need to obtain permission directly from the copyright holder. To view a copy of this licence, visit http:// creativecommons.org/licenses/by/4.0/.

\section{REFERENCES}

Baker SM, Plug AW, Prolla TA, Bronner CE, Harris AC, Yao X, Christie DM, Monell C, Arnheim N, Bradley A et al (1996) Involvement of mouse Mlh1 in DNA mismatch repair and meiotic crossing over. Nat Genet 13:336-342

Barlow DP, Bartolomei MS (2014) Genomic imprinting in mammals. Cold Spring Harb Perspect Biol. https://doi.org/10.1101/ cshperspect.a018382

Barton SC, Surani MA, Norris ML (1984) Role of paternal and maternal genomes in mouse development. Nature 311:374-376

Blasco MA, Serrano M, Fernandez-Capetillo O (2011) Genomic instability in iPS: time for a break. EMBO J 30:991-993

Buccione R, Schroeder AC, Eppig JJ (1990) Interactions between somatic cells and germ cells throughout mammalian oogenesis. Biol Reprod 43:543-547

Chen Z, Liu Z, Huang J, Amano T, Li C, Cao S, Wu C, Liu B, Zhou L, Carter MG et al (2009) Birth of parthenote mice directly from parthenogenetic embryonic stem cells. Stem Cells 27:2136-2145

Chuva de Sousa Lopes SM, Hayashi K, Shovlin TC, Mifsud W, Surani MA, McLaren A (2008) X chromosome activity in mouse XX primordial germ cells. PLoS Genet 4:e30

D'Antonio M, Benaglio P, Jakubosky D, Greenwald WW, Matsui $H$, Donovan MKR, Li H, Smith EN, D'Antonio-Chronowska A, Frazer KA (2018) Insights into the mutational burden of human induced pluripotent stem cells from an integrative multi-omics approach. Cell Rep 24:883-894

Davis TL, Yang GJ, McCarrey JR, Bartolomei MS (2000) The H19 methylation imprint is erased and re-established differentially on the parental alleles during male germ cell development. Hum Mol Genet 9:2885-2894

De Sousa PA, Wilmut I (2007) Human parthenogenetic embryo stem cells: appreciating what you have when you have it. Cell Stem Cell 1:243-244

De Bonis ML, Ortega S, Blasco MA (2014) SIRT1 is necessary for proficient telomere elongation and genomic stability of induced pluripotent stem cells. Stem Cell Rep 2:690-706

Didie M, Christalla P, Rubart M, Muppala V, Doker S, Unsold B, ElArmouche A, Rau T, Eschenhagen T, Schwoerer AP et al (2013) Parthenogenetic stem cells for tissue-engineered heart repair. J Clin Investig 123:1285-1298 
Edelmann W, Cohen PE, Kane M, Lau K, Morrow B, Bennett S, Umar A, Kunkel T, Cattoretti G, Chaganti R et al (1996) Meiotic pachytene arrest in MLH1-deficient mice. Cell 85:1125-1134

Eggan K, Akutsu H, Loring J, Jackson-Grusby L, Klemm M, Rideout WM III, Yanagimachi R, Jaenisch R (2001) Hybrid vigor, fetal overgrowth, and viability of mice derived by nuclear cloning and tetraploid embryo complementation. Proc Natl Acad Sci USA 98:6209-6214

Eppig JJ, O'Brien MJ, Wigglesworth K, Nicholson A, Zhang W, King BA (2009) Effect of in vitro maturation of mouse oocytes on the health and lifespan of adult offspring. Hum Reprod 24:922-928

Espejel S, Eckardt S, Harbell J, Roll GR, McLaughlin KJ, Willenbring H (2014) Brief report: parthenogenetic embryonic stem cells are an effective cell source for therapeutic liver repopulation. Stem Cells 32:1983-1988

Gao S, Zheng C, Chang G, Liu W, Kou X, Tan K, Tao L, Xu K, Wang $\mathrm{H}$, Cai $\mathrm{J}$ et al (2015) Unique features of mutations revealed by sequentially reprogrammed induced pluripotent stem cells. Nat Commun 6:6318

Geijsen N, Horoschak M, Kim K, Gribnau J, Eggan K, Daley GQ (2004) Derivation of embryonic germ cells and male gametes from embryonic stem cells. Nature 427:148-154

Gore A, Li Z, Fung HL, Young JE, Agarwal S, Antosiewicz-Bourget J, Canto I, Giorgetti A, Israel MA, Kiskinis E et al (2011) Somatic coding mutations in human induced pluripotent stem cells. Nature 471:63-67

Grive KJ, Freiman RN (2015) The developmental origins of the mammalian ovarian reserve. Development 142:2554-2563

Hackett JA, Huang Y, Gunesdogan U, Gretarsson KA, Kobayashi T, Surani MA (2018) Tracing the transitions from pluripotency to germ cell fate with CRISPR screening. Nat Commun 9:4292

Hajkova P, Erhardt S, Lane N, Haaf T, El-Maarri O, Reik W, Walter J, Surani MA (2002) Epigenetic reprogramming in mouse primordial germ cells. Mech Dev 117:15-23

Handel MA, Eppig JJ, Schimenti JC (2014) Applying "Gold Standards" to in-vitro-derived germ cells. Cell 159:216

Hayashi K, Saitou M (2013) Generation of eggs from mouse embryonic stem cells and induced pluripotent stem cells. Nat Protoc 8:1513-1524

Hayashi K, Ogushi S, Kurimoto K, Shimamoto S, Ohta H, Saitou M (2012) Offspring from oocytes derived from in vitro primordial germ cell-like cells in mice. Science 338:971-975

Hikabe O, Hamazaki N, Nagamatsu G, Obata Y, Hirao Y, Hamada N, Shimamoto S, Imamura T, Nakashima K, Saitou M et al (2016) Reconstitution in vitro of the entire cycle of the mouse female germ line. Nature 539:299-303

Hochberg Y, Benjamini $Y$ (1990) More powerful procedures for multiple significance testing. Stat Med 9:811-818

Huang J, Deng K, Wu H, Liu Z, Chen Z, Cao S, Zhou L, Ye X, Keefe $D L$, Liu $L$ (2008) Efficient production of mice from embryonic stem cells injected into four- or eight-cell embryos by piezo micromanipulation. Stem Cells 26:1883-1890

Huang K, Maruyama T, Fan G (2014) The naive state of human pluripotent stem cells: a synthesis of stem cell and preimplantation embryo transcriptome analyses. Cell Stem Cell 15:410-415
Irie N, Weinberger L, Tang WW, Kobayashi T, Viukov S, Manor YS, Dietmann S, Hanna JH, Surani MA (2015) SOX17 is a critical specifier of human primordial germ cell fate. Cell 160:253-268

Johannesson B, Sagi I, Gore A, Paull D, Yamada M, Golan-Lev T, Li Z, LeDuc C, Shen Y, Stern S et al (2014) Comparable frequencies of coding mutations and loss of imprinting in human pluripotent cells derived by nuclear transfer and defined factors. Cell Stem Cell 15:634-642

Kagiwada S, Kurimoto K, Hirota T, Yamaji M, Saitou M (2013) Replication-coupled passive DNA demethylation for the erasure of genome imprints in mice. EMBO J 32:340-353

Kilpinen H, Goncalves A, Leha A, Afzal V, Alasoo K, Ashford S, Bala S, Bensaddek D, Casale FP, Culley OJ et al (2017) Common genetic variation drives molecular heterogeneity in human iPSCs. Nature 546:370-375

Kim K, Lerou P, Yabuuchi A, Lengerke C, Ng K, West J, Kirby A, Daly MJ, Daley GQ (2007) Histocompatible embryonic stem cells by parthenogenesis. Science 315:482-486

Li C, Chen Z, Liu Z, Huang J, Zhang W, Zhou L, Keefe DL, Liu L (2009) Correlation of expression and methylation of imprinted genes with pluripotency of parthenogenetic embryonic stem cells. Hum Mol Genet 18:2177-2187

Li Z, Wan H, Feng G, Wang L, He Z, Wang Y, Wang XJ, Li W, Zhou Q, Hu B (2016) Birth of fertile bimaternal offspring following intracytoplasmic injection of parthenogenetic haploid embryonic stem cells. Cell Res 26:135-138

Lin G, OuYang Q, Zhou X, Gu Y, Yuan D, Li W, Liu G, Liu T, Lu G (2007) A highly homozygous and parthenogenetic human embryonic stem cell line derived from a one-pronuclear oocyte following in vitro fertilization procedure. Cell Res 17:999-1007

Liu L, Trimarchi JR, Keefe DL (2002) Haploidy but not parthenogenetic activation leads to increased incidence of apoptosis in mouse embryos. Biol Reprod 66:204-210

Liu L, Franco S, Spyropoulos B, Moens PB, Blasco MA, Keefe DL (2004) Irregular telomeres impair meiotic synapsis and recombination in mice. Proc Natl Acad Sci USA 101:6496-6501

Liu Z, Hu Z, Pan X, Li M, Togun TA, Tuck D, Pelizzola M, Huang J, Ye X, Yin Y et al (2011) Germline competency of parthenogenetic embryonic stem cells from immature oocytes of adult mouse ovary. Hum Mol Genet 20:1339-1352

Liu M, Yin Y, Ye X, Zeng M, Zhao Q, Keefe DL, Liu L (2013) Resveratrol protects against age-associated infertility in mice. Hum Reprod 28:707-717

Lucifero D, Mertineit C, Clarke HJ, Bestor TH, Trasler JM (2002) Methylation dynamics of imprinted genes in mouse germ cells. Genomics 79:530-538

Mai Q, Yu Y, Li T, Wang L, Chen MJ, Huang SZ, Zhou C, Zhou Q (2007) Derivation of human embryonic stem cell lines from parthenogenetic blastocysts. Cell Res 17:1008-1019

Miyauchi H, Ohta H, Nagaoka S, Nakaki F, Sasaki K, Hayashi K, Yabuta Y, Nakamura T, Yamamoto T, Saitou M (2017) Bone morphogenetic protein and retinoic acid synergistically specify female germ-cell fate in mice. EMBO J 36:3100-3119

Miyoshi N, Stel JM, Shioda K, Qu N, Odajima J, Mitsunaga S, Zhang X, Nagano M, Hochedlinger K, Isselbacher KJ et al (2016) Erasure of DNA methylation, genomic imprints, and epimutations 
in a primordial germ-cell model derived from mouse pluripotent stem cells. Proc Natl Acad Sci USA 113:9545-9550

Moses RM, Kline D (1995) Calcium-independent, meiotic spindledependent metaphase-to-interphase transition in phorbol estertreated mouse eggs. Dev Biol 171:111-122

Nagaoka SI, Hassold TJ, Hunt PA (2012) Human aneuploidy: mechanisms and new insights into an age-old problem. Nat Rev Genet 13:493-504

Nagy A, Rossant J, Nagy R, Abramow-Newerly W, Roder JC (1993) Derivation of completely cell culture-derived mice from earlypassage embryonic stem cells. Proc Natl Acad Sci USA 90:8424-8428

Ohinata Y, Ohta H, Shigeta M, Yamanaka K, Wakayama T, Saitou M (2009) A signaling principle for the specification of the germ cell lineage in mice. Cell 137:571-584

Ohta H, Kurimoto K, Okamoto I, Nakamura T, Yabuta Y, Miyauchi H, Yamamoto T, Okuno Y, Hagiwara M, Shirane K et al (2017) In vitro expansion of mouse primordial germ cell-like cells recapitulates an epigenetic blank slate. EMBO J 36:1888-1907

Pasque V, Tchieu J, Karnik R, Uyeda M, Sadhu Dimashkie A, Case D, Papp B, Bonora G, Patel S, Ho R et al (2014) X chromosome reactivation dynamics reveal stages of reprogramming to pluripotency. Cell 159:1681-1697

Picelli S, Faridani OR, Bjorklund AK, Winberg G, Sagasser S, Sandberg R (2014) Full-length RNA-seq from single cells using Smart-seq2. Nat Protoc 9:171-181

Qing T, Liu H, Wei W, Ye X, Shen W, Zhang D, Song Z, Yang W, Ding $M$, Deng $H$ (2008) Mature oocytes derived from purified mouse fetal germ cells. Hum Reprod 23:54-61

Reik W, Dean W, Walter J (2001) Epigenetic reprogramming in mammalian development. Science 293:1089-1093

Revazova ES, Turovets NA, Kochetkova OD, Kindarova LB, Kuzmichev LN, Janus JD, Pryzhkova MV (2007) Patient-specific stem cell lines derived from human parthenogenetic blastocysts. Cloning Stem Cells 9:432-449

Sagi I, Chia G, Golan-Lev T, Peretz M, Weissbein U, Sui L, Sauer MV, Yanuka O, Egli D, Benvenisty N (2016) Derivation and differentiation of haploid human embryonic stem cells. Nature 532:107-111

Sagi I, De Pinho JC, Zuccaro MV, Atzmon C, Golan-Lev T, Yanuka O, Prosser R, Sadowy A, Perez G, Cabral T et al (2019) Distinct imprinting signatures and biased differentiation of human androgenetic and parthenogenetic embryonic stem cells. Cell Stem Cell 25:419-432.e419

SanMiguel JM, Bartolomei MS (2018) DNA methylation dynamics of genomic imprinting in mouse development. Biol Reprod 99:252262

Sasaki K, Yokobayashi S, Nakamura T, Okamoto I, Yabuta Y, Kurimoto K, Ohta H, Moritoki Y, Iwatani C, Tsuchiya H et al (2015) Robust in vitro induction of human germ cell fate from pluripotent stem cells. Cell Stem Cell 17:178-194

Seisenberger S, Andrews S, Krueger F, Arand J, Walter J, Santos F, Popp C, Thienpont B, Dean W, Reik W (2012) The dynamics of genome-wide DNA methylation reprogramming in mouse primordial germ cells. Mol Cell 48:849-862
Shen W, Zhang D, Qing T, Cheng J, Bai Z, Shi Y, Ding M, Deng H (2006) Live offspring produced by mouse oocytes derived from premeiotic fetal germ cells. Biol Reprod 75:615-623

Sheng X, Tian C, Liu L, Wang L, Ye X, Li J, Zeng M, Liu L (2019) Characterization of oogonia stem cells in mice by Fragilis. Protein Cell 10:825-831

Shirane K, Kurimoto K, Yabuta Y, Yamaji M, Satoh J, Ito S, Watanabe A, Hayashi K, Saitou M, Sasaki H (2016) Global landscape and regulatory principles of DNA methylation reprogramming for germ cell specification by mouse pluripotent stem cells. Dev Cell 39:87-103

Stelzer Y, Ronen D, Bock C, Boyle P, Meissner A, Benvenisty N (2013) Identification of novel imprinted differentially methylated regions by global analysis of human-parthenogenetic-induced pluripotent stem cells. Stem Cell Rep 1:79-89

Surani MA, Barton SC, Norris ML (1984) Development of reconstituted mouse eggs suggests imprinting of the genome during gametogenesis. Nature 308:548-550

Swann K, Ozil JP (1994) Dynamics of the calcium signal that triggers mammalian egg activation. Int Rev Cytol 152:183-222

Tam PP, Zhou SX, Tan SS (1994) X-chromosome activity of the mouse primordial germ cells revealed by the expression of an X-linked lacZ transgene. Development 120:2925-2932

Tapia N, Scholer HR (2016) Molecular obstacles to clinical translation of iPSCs. Cell Stem Cell 19:298-309

Theunissen TW, Friedli M, He Y, Planet E, O'Neil RC, Markoulaki S, Pontis J, Wang H, louranova A, Imbeault M et al (2016) Molecular criteria for defining the naive human pluripotent state. Cell Stem Cell 19:502-515

Tian C, Liu L, Ye X, Fu H, Sheng X, Wang L, Wang H, Heng D, Liu L (2019) Functional oocytes derived from granulosa cells. Cell Rep 29:4256-4267.e4259

von Meyenn F, Berrens RV, Andrews S, Santos F, Collier AJ, Krueger F, Osorno R, Dean W, Rugg-Gunn PJ, Reik W (2016) Comparative principles of DNA methylation reprogramming during human and mouse in vitro primordial germ cell specification. Dev Cell 39:104-115

Wang L, Zhang J, Duan J, Gao X, Zhu W, Lu X, Yang L, Zhang J, Li G, Ci W et al (2014) Programming and inheritance of parental DNA methylomes in mammals. Cell 157:979-991

Xie W, Barr CL, Kim A, Yue F, Lee AY, Eubanks J, Dempster EL, Ren B (2012) Base-resolution analyses of sequence and parent-oforigin dependent DNA methylation in the mouse genome. Cell 148:816-831

Yamashiro C, Sasaki K, Yabuta Y, Kojima Y, Nakamura T, Okamoto I, Yokobayashi S, Murase Y, Ishikura Y, Shirane K et al (2018) Generation of human oogonia from induced pluripotent stem cells in vitro. Science 362:356-360

Yin Y, Liu N, Ye X, Guo R, Hao J, Wang F, Liu L (2014) Telomere elongation in parthenogenetic stem cells. Protein Cell 5:8-11

Yoshihara M, Araki R, Kasama Y, Sunayama M, Abe M, Nishida K, Kawaji H, Hayashizaki Y, Murakawa Y (2017) Hotspots of de novo point mutations in induced pluripotent stem cells. Cell Rep 21:308-315

Yuan L, Liu JG, Zhao J, Brundell E, Daneholt B, Hoog C (2000) The murine SCP3 gene is required for synaptonemal complex 
assembly, chromosome synapsis, and male fertility. Mol Cell 5:73-83

Zhang H, Liu K (2015) Cellular and molecular regulation of the activation of mammalian primordial follicles: somatic cells initiate follicle activation in adulthood. Hum Reprod Update 21:779-786
Zhou Q, Wang M, Yuan Y, Wang X, Fu R, Wan H, Xie M, Liu M, Guo $X$, Zheng $Y$ et al (2016) Complete meiosis from embryonic stem cell-derived germ cells in vitro. Cell Stem Cell 18:330-340 